\title{
A Comparative Analysis of Immigrant Skills and Their Utilization in Australia, Canada, and the United States
}

\author{
Andrew Clarke*and Mikal Skuterud ${ }^{\dagger}$
}

March 10, 2016

\begin{abstract}
We compare literacy test scores and their impact on wage and employment outcomes of Australian, Canadian, and U.S. immigrants. Overall, we find little to distinguish the skills of immigrants to these three countries, although there is some indication of gains at the lower end of the distribution among Australian immigrants arriving after the mid-1990s. Relative immigrant wage returns to literacy are, however, substantially higher in the U.S., which we argue reflects language-skill complementarities, as opposed to more efficient skill utilization or unobserved productivity characteristics.
\end{abstract}

Keywords: Immigrant workers; labour market integration; immigrant selection policy. JEL Classification: J61, J31, J23.

${ }^{*}$ Lecturer, Department of Economics, University of Melbourne, Level 4, Faculty of Business and Economics Building, 111 Barry Street, Carlton, Victoria, Australia; andrew.clarke@unimelb.edu.au.

${ }^{\dagger}$ Associate Professor, Department of Economics, University of Waterloo, 200 University Avenue West, Waterloo, Ontario, Canada, N2L 3G1; skuterud@uwaterloo.ca. 


\section{Introduction}

Recent years have save seen a shift in the discourse surrounding national immigration policies towards a greater emphasis on economic objectives and, in particular, the goal of attracting skilled

migrants. This has been most evident in immigration reform discussions in the U.S., where there has been a renewed push for more merit-based immigration in place of long-standing family reunification objectives. However, it is also evident in the U.K., where a point system for selecting skilled migrants was phased in between 2008 and 2010, and in Australia and Canada, where more than three decades after introducing point systems, policymakers continue to grapple with finding the optimal set of criteria for screening prospective migrants.

While selective immigration policies in Australia and Canada have clearly raised the average education levels of immigrants (Antecol, Cobb-Clark and Trejo 2003; Aydemir 2014), the extent to which it has raised the actual skills of immigrants valued by Australian and Canadian employers is less clear. In Canada, for example, large increases in the share of new immigrants with university degrees over the past three decades did not translate into higher average immigrant earnings (Aydemir and Skuterud 2005). Moreover, there is a concern that inefficiencies in domestic labour market institutions and immigrant settlement policies may result in an under-utilization of immigrant skills, through for example information frictions in the recognition of foreign education credentials.

Critical to informing the effects of immigrant selection and settlement policies on immigrant skills and their utilization is being able to measure skills directly, as opposed to education levels or the relative earnings of immigrants. This article contributes to the current literature in three respects. First, we compare literacy test scores of Australian, Canadian, and U.S. immigrants using data from the 2003/2006 Adult Literacy and Life Skills Survey (ALLS), a survey designed to enable inter-country comparisons of adult literacy skills. Although literacy is only one dimension of workplace skill, existing research has interpreted these test scores broadly as cognitive skill (e.g., Green and Riddell 2003; Kahn 2004; Ferrer, Green and Riddell 2006; Blau and Kahn 2005; Barrett 2012; Bratsberg, Hægeland and Raaum 2013). Moreover, because the tests are completed in the official language of the host country, they also have the potential to capture the language abilities of individuals with a foreign native language.

Second, Australia's immigration reforms in the late 1990s provide an opportunity to inform the potential for selection policy to increase skills. Specifically, in the late 1990s Australia not only expanded the number of visas in the skill-based categories (points system), but also placed greater emphasis on productivity related factors in the admission of skilled immigrants, including a greater emphasis on pre-arranged employment, the introduction of mandatory pre-migration language test- 
ing, and a greater emphasis on educational qualifications acquired in Australia. Differences in the average literacy skills of recent Australian immigrants, relative to established Australian immigrants and recent immigrants in Canada and the U.S., provides some indication of the effect of these reforms on immigrant skills.

Finally, consistent with our interpretation of literacy test scores as cognitive skill, we measure skill utilization as the log wage return to immigrant skills relative to the comparable return for native-born workers. To the extent that immigrant skills are being under-utilized, perhaps due to employer challenges in evaluating foreign educational credentials, the log wage return to their measured skills should be lower than for natives. Moreover, we also examine the impact of immigrants' literacy skills on the literacy requirements of the occupations in which immigrants are employed using the $\mathrm{O}^{*} \mathrm{NET}$ database. Evidence of a weaker impact of measured literacy on the literacy requirements of jobs among immigrants provides evidence consistent with skill under-utilization.

Our main finding is that, among immigrants with a foreign mother tongue (that is not Spanish in the U.S. case), skills appear virtually identical all three countries, at least above the 20th percentile. This result is consistent with the findings of Antecol, Cobb-Clark, and Trejo (2003) measuring skill using educational attainment and self-reported language ability. However, consistent with the findings of Cobb-Clark (2003) based on educational attainment and self-reported English language ability, our results indicate that average literacy among all recent immigrants in Australia was, by the mid-2000s, significantly higher than in either Canada or the United States. In particular, Australia's immigration reforms of the late 1990s appear to have been successful in substantially reducing the proportion of Australian immigrants with literacy levels below the threshold at which individuals are deemed functionally illiterate. Finally, we find no evidence of immigrant skill under-utilization. Rather, the labour market returns to the literacy skills of Australian and Canadian immigrants are not statistically different from their native-born counterparts. However, our estimates do point to a higher relative return to literacy for U.S. immigrants whose mother tongue is neither English nor Spanish. We argue that this finding reflects a complementarity between language skills and cognitive skills, coupled with a higher return to cognitive skill for all workers in the United States.

The remainder of the paper is organized as follows. In the following section we provide background discussion of the most relevant policy and institutional differences between Australia, Canada and the United States. We then describe the ALLS data in detail. In the fourth section, we present our results by first considering differences in relative immigrant literacy test scores and then examine the labour market returns to these scores. We conclude with a discussion of what we see as the key policy differences that are likely to be driving the main findings. 


\section{Background}

In terms of immigrant skill levels, we expect the U.S. to attract a greater flow of unskilled immigrants, due primarily to the existence of large undocumented migration flows from Latin America, but also because of its greater emphasis on family reunification objectives, as opposed to human capital screening, in immigrant selection policy. On the other hand, more generous minimum wages in Australia and a greater union presence in Canada will tend to raise wages at the lower end of the wage distribution, relative to the United States. Inasmuch as these wage differentials do not create barriers to immigrant employment, we would expect them to attract unskilled migrant flows. Overall, if we were to look beyond migration from Latin America, we might then expect to find weaker immigrant skills at the lower end of the distribution in Australia and Canada.

Factors that influence immigrant selection at the upper end of the distribution are, however, different. Conditioning on immigrants from a similar set of source countries, we expect U.S. immigration flows to dominate, due primarily to larger wage returns to skill in the U.S., combined with relatively low marginal income tax rates at the upper end of the income distribution (Borjas 1987). Additionally, a relatively small but important segment of immigrants to the U.S. are admitted directly as skilled workers or on temporary student visas and then transition to permanent status after obtaining employment in the United States. Inasmuch as employers are able to extract better information to identify exceptional talent, relative to the broad criteria of the points system, there is further reason to expect the skills of U.S. immigrants to dominate at the top end of the distribution. Lastly, if for some reason the U.S. is more attractive to all immigrants, regardless of skill level, for example if all immigrants perceive there is greater opportunity in the U.S. (including for their children), then there will be queues for migration to the United States. Combined with employer selection for skilled workers, this should provide the U.S. with a further advantage in the skills of immigrants at the top end of the distribution.

Effective immigration policy must not only attract skilled migrants, but also insure efficient utilization of their skills following their arrival. A critical consideration in this respect are foreigneducated immigrants, who may have adequate skills, but have difficulties obtaining employment commensurate with their skills if there are information frictions in evaluating their foreign credentials or if their skills are not in demand in the host country. The crudeness of the Canadian immigration policy, particularly the absence of a credential assessment process and criteria based on current labour market needs criteria, suggests skill utilization should be least efficient in Canada. ${ }^{1}$ Although the share of immigrants admitted through employer selection is quite small, employer pre-

\footnotetext{
${ }^{1}$ Note that Canada has followed the Australian lead and introduced pre-migration credential recognition systems since the data we examine were collected.
} 
migration vetting of immigrant credentials in U.S. makes skill utilization issues less likely there. Consequently, we expect relative wage returns to immigrant skills to be lowest in Canada, followed by Australia and the United States.

Finally, we have argued that labour market institutions that regulate wage rates are most prevalent in Australia, followed by Canada. A consequence of these institutions may be that immigrant literacy deficits or information frictions that make it difficult for employers to evaluate immigrant skills manifest themselves through low employment rates, as opposed to wage rates. Consistent with this idea, Antecol, Kuhn and Trejo (2006) find that whereas immigrant assimilation in the U.S. is evident primarily through weekly earnings, in Australia it is more evident in relative employment rates. Two recent audit studies of local Canadian labour markets (Oreopoulos 2011, Dechief and Oreopoulos 2012), showing lower employer interview requests for applicants with 'non-English' sounding names, similarly highlight the importance of the employment margin in understanding the labour market challenges of Canadian immigrants. This emphasizes the importance of considering both wage and employment returns to immigrant literacy skills in evaluating relative skill utilization across immigrant destination countries.

Notwithstanding these considerations, the deregulation of Australian labour markets in the 1990s, most notably the dismantling of its awards system for setting wages across entire sectors, as well as new restrictions on access to income support programs among new immigrants, should have stemmed unskilled immigration flows. In addition, during the latter half of the 1990s Australia experienced a significant reform in both its immigrant selection and settlement policies. Specifically, the share of immigrants admitted under the skilled migration program expanded from $18.3 \%$ for the year $1993-94$ to $33.2 \%$ for the year 1999-2000. ${ }^{2}$ In addition, immigrants admitted under the skilled migration program were now required to meet a minimum age requirement (under 45 years), be proficient in English at a vocational level, have their qualifications assessed before they apply for admission, and satisfy requirements for an occupation or skill in demand. This latter requirement could be satisfied through either pre-arranged employment or relevant source country experience in the occupation (Richardson and Lester 2004). Finally, in an effort to better facilitate the transition of foreign-born residents from temporary visas to permanent resident status, Australia waived the work experience requirement for students completing qualifications at an Australian educational institution, effectively placing greater weight on Australian qualifications in the points system. As well, a new temporary visa was introduced allowing employers to sponsor skilled overseas workers to work in Australia temporarily. As of July 2013, the minimum annual income for workers admitted under a temporary work permit is $\$ 53,900$ per year. This is below median earnings, but well above

\footnotetext{
${ }^{2}$ Department of Immigration and Border Protection, Immigration Update.
} 
the earnings of minimum wage workers of $\$ 32,350$. Gregory (2014) documents the evolution of a 'two-step' system in Australia, in which immigrants first admitted with a temporary visa transition to permanent status after accumulating local labour market skills, improving the long-run labour market integration of permanent immigrants.

In summary, differences in immigrant selection policies, as well as domestic labour market institutions and geography, should produce higher skills at the lower end of the distribution in the U.S., followed by Canada and Australia. However, Australian policy changes of the late 1990s, should have substantially reduced unskilled migration flows to Australia, potentially reversing its position relative to Canada, and perhaps also the United States. In addition, endogenous responses to these policy reforms are likely to alter the distribution of immigrants across visa categories and the source country distribution of Australian immigrants. At the upper end of the skills distribution, on the other hand, we expect the U.S. immigrants to dominate, due to both self-selection and the role of employers in immigrant selection. Finally, due primarily to the contrast in information available to employers, relative to the broad criteria of point systems, we expect immigrant returns to literacy skills to be highest in the U.S., followed by Australia and Canada. However, once again, Australian policy reforms providing employers with a greater role in selection, may not only have raised immigrant skills, but also resulted in higher labour market returns to those skills.

\section{Data}

The Adult Literacy and Life Skills Survey (ALLS) was the second initiative of Statistics Canada and the Organisation for Economic Co-operation and Development (OECD) to collect internationally comparable data measuring adult literacy skills. ${ }^{3}$ In addition to providing objective measures of literacy and numeracy skills, the ALLS provides information on a rich set of individual economic and social characteristics, including country of birth and year of migration. In Canada and the United States, data collection took place in 2003 (in Canada between March and September and in the U.S. between January and June), while in Australia data were collected between July 2006 and January 2007.

The ALLS data facilitate international comparisons since each country used the same psychometric test to assess skills across three domains, prose literacy, document literacy, and numeracy. The assessment of these skills involved questions that emphasized the implementation and use of these skills in daily activities. It is this emphasis on 'essential skills' that makes the data particularly useful for estimating an overall return to skill across labour markets within a country. Proficiency

\footnotetext{
${ }^{3}$ The International Adult Literacy Survey (IALS) was conducted in 23 countries, including Australia, Canada and the U.S., between 1993 and 1998. We were unable to use these data as only public-use files, which provide limited information on labour market earnings, were available for Australia and United States.
} 
in all domains is measured along a continuous scale ranging from 0 to 500 .

Consistent with Green and Riddell (2003), Kahn (2004), and Barrett (2012), we find that individuals' scores are highly correlated across the three skill domains, making it difficult to separately identify the effect of each skill domain on employment or earnings outcomes. Rather than combine domains, which would invalidate our variance estimation procedure, we completed our analysis separately using each of the three skill domains. However, for the sake of brevity, we only report the results for document literacy, which we think is most likely to capture the vocational skills critical for immigrant labour market integration. Although none of our main findings are sensitive to the choice of domain, the precision of the estimated immigrant wage returns was in some cases improved when using document literacy.

A limitation of the ALLS literacy assessment is that it is primarily intended to capture basic functional literacy, rather than higher-order cognitive skills. Consequently, the data are more informative about the skills of workers at the lower end of the skill distribution than at the top. Indeed, among native-born workers with a university degree, we find virtually no evidence of a wage return to the ALLS literacy test scores in either the Australian or Canadian data. ${ }^{4}$ However, for immigrants an important part of the test score variation reflects language abilities. Evidence of this is that, in contrast to native-born workers, there is a significant wage return to measured literacy even among university-educated immigrants in both Australia and Canada. ${ }^{5}$ For this reason, variation in the ALLS test scores are informative about the labour market skills of immigrants, even at the upper end of the distribution.

The analysis presented in this paper utilizes the continuous earnings data, detailed year of arrival, and country of birth for immigrants that is only available in the restricted use releases of the data for all three countries. ${ }^{6}$ Several sample restrictions are imposed in order to create a consistent sample across destination countries. First, samples are restricted to individuals currently aged 18-64. Second, students and the self-employed are also excluded, as cognitive skills play a weaker role in determining their labour market outcomes. Third, in order to avoid spurious correlations in our sample between age at migration and years since migration, arising as a consequence of our overall age restriction, we also exclude all immigrants who migrated before the age of 14 . Finally,

\footnotetext{
${ }^{4}$ There is an important question about why there exists any variation in test scores among university-educated workers, given the basic skills that the test questions are intended to capture. Our understanding is that the variation is primarily a consequence of the item response theory (IRT) methodology used to estimate the test scores. In essence, estimated plausible values depend in part on the difficulty of the questions that one randomly receives. Consequently, an important part of the variation in plausible values at the upper end of the distribution is entirely random.

${ }^{5}$ Insufficient sample size prohibits conducting this exercise for immigrants in the U.S. sample. The results for Australia and Canada are available from the authors.

${ }^{6}$ For Australia, the data were accessed through the Australian Bureau of Statistics' remote access system, while for Canada and the United States they were accessed through a secure facility approved by Statistics Canada and the National Center for Education Statistics (NCES), respectively.
} 
the principal outcome of interest is the hourly wage rate on the main job held over the previous year, which is constructed using information on weekly earnings in the main job and usual hours of work per week in this job. In order to ensure that the estimates are not driven by extreme observations in the earnings distribution, individuals in approximately $1 \%$ of the top and bottom of the earnings distributions are excluded from the analysis.

There are important differences in the source country composition of immigrants in these countries reflecting historical immigration policies and geographic proximity. The U.S., for example, has larger immigration flows from Mexico, and Australia from New Zealand. We would not, however, want to attribute differences in average immigrant literacy skills that arise from these flows to current immigration policies. Utilizing information on respondents' first language learned and understood, allows us to distinguish immigrants according to whether or not they have a native mother tongue (English in Australia or the United States; English or French in Canada). ${ }^{7}$ Moreover, for the United States we can also distinguish immigrants with a Spanish mother tongue. By comparing U.S. immigrants with a foreign mother tongue that is not Spanish to Australian and Canadian immigrants with a foreign mother tongue (non-English in Australia and non-English/French in Canada), we obtain samples that are much more similar in source country composition. ${ }^{8}$

\section{INSERT TABLE 1 HERE}

Table 1 reports sample means in our extracted immigrant and native-born samples from the Australian, Canadian and U.S. ALLS data. With regard to immigrants, Table 1 reveals large differences in the relative educational attainment and occupations of immigrants across destination countries. The share of Australian and Canadian immigrants with university qualifications is similar at $32.6 \%$ and $32.2 \%$, respectively, which in both countries is significantly greater than the share of native-born individuals with university qualifications. In contrast, in the U.S., the share of university qualified immigrants is more similar, at $31.3 \%$, to the share of native-born Americans with a university qualification. Similarly, the share of immigrants in white collar jobs is higher in Australia (33.0\%) and Canada (28.1\%) than in the U.S. (24.0\%), while the share in both skilled and unskilled blue collar jobs is higher in the U.S. (30.3\% compared to $16.3 \%$ in Australia and $26.7 \%$ in Canada). These differences presumably reflect the emphasis of the Australian and Canadian point

\footnotetext{
${ }^{7}$ While it is possible to identify whether an individual was born outside the country of interview for all three destination countries, no further information regarding country of birth is available for the U.S., and in Australia and Canada the information is limited to a small set of the largest source countries.

${ }^{8}$ Using Census data, we compared the top 20 foreign-language immigrant source countries based on official languages. Excluding the set of Spanish countries from the U.S. data, the results reveal remarkable overlap in the set of countries, suggesting that U.S. immigrants with a non-Spanish mother tongue are not substantially different in origin from Australian and Canadian immigrants with a foreign mother tongue. The results are available from the authors upon request.
} 
systems on post-secondary qualifications. This, however, masks some important heterogeneity between mother tongue groups within the U.S.. While less than $10 \%$ of U.S. immigrants with a Spanish mother tongue have university qualifications, over $50 \%$ of U.S. immigrants with a foreign mother tongue that is not Spanish do. By comparison, 35.4\% of Australian and $31.2 \%$ of Canadian immigrants with a foreign mother tongue have a university qualification.

\section{INSERT TABLE 2 HERE}

Table 2 reports the proportions of immigrants with and without a foreign mother tongue separately for recent immigrants, that is those arriving in the destination country within the previous 10 years, and established immigrants. Reflecting the persistent effect of historical immigration policy favoring migrants from English-speaking countries, as well as proximity to New Zealand, 40\% of immigrants to Australia have a native mother tongue. The corresponding shares are $22.8 \%$ and $15.7 \%$ in Canada and the U.S., respectively. Among U.S. immigrants with a non-English mother tongue (approximately $85 \%$ of all immigrants), roughly half have a Spanish mother tongue, while the rest provide the group of greatest interest when comparing to foreign-language immigrants in Australia and Canada. Unfortunately, the ALLS sample size for the U.S. is small, leaving us with only 97 immigrants in this non-Spanish foreign mother tongue category. Nonetheless, robust differences for U.S. immigrants are evident in the data across all skill domains, in terms of both the literacy skill levels and labour market outcomes. Also, the fact that in all three destination countries roughly $40 \%$ of immigrants are observed within 10 years of their arrival, provides sufficient sample sizes to shed some light on the influence of recent immigration policies, particularly in the case of Australia.

\section{Results}

\subsection{Relative Immigrant Literacy}

\section{INSERT TABLE 3 HERE}

We begin our analysis of immigrant skills by comparing mean document literacy scores between Australian, Canadian, and U.S. immigrants. Table 3 reports sample means separately by immigrants' gender, age, education, occupation, mother tongue and years since arrival. In all three destination countries, the mean literacy score in the full sample of all immigrants is lower than in the native-born population, despite immigrants having greater levels of educational attainment. The difference is greatest in the U.S. and smallest in Australia, and is in all cases statistically significant. In the U.S., the immigrant gap is equivalent to the difference between the 48th and 18th percentiles of the U.S. native-born distribution, whereas in Australia it is the difference be- 
tween the 47th and 27th percentiles, and in Canada, the 47th and 21st. Comparing directly across destination countries, mean immigrant literacy skills are highest in Australia (255.8), followed by Canada (248.1) and the United States (228.6). ${ }^{9}$

Further examination of Table 3 reveals that source country distributions are important in explaining the differences in average immigrant literacy across destination countries. Approximately $40 \%$ of immigrants to Australia have a native mother tongue and these immigrants have higher average test scores in all countries, particularly in Australia. Similarly, about $44 \%$ of immigrants to the U.S. have a Spanish mother tongue and their literacy test scores are, on average, exceptionally low. To shed light on the efficacy of selection policy in raising average immigrant skills, it is important that we account for these broad native language differences, since they are by and large driven by factors beyond the influence of current immigration policy, most notably geography and history. Comparing recent Australian immigrants with a foreign mother tongue to recent U.S. immigrants with a foreign mother tongue that is not Spanish, the mean skill scores of recent immigrants are remarkably similar across countries and not statistically distinguishable (256.6, 248.0, and 253.6, respectively). Hence, comparing across a similar distribution of source countries, there is little evidence of differences in the mean skill of immigrants in the three host countries.

However, Table 3 also indicates that the average skill level of Australian immigrants arriving after 1995 is substantially higher than among earlier cohorts (271.9 compared to 245.6). This large advantage for more recent immigrants is not evident in either Canada or the United States. Although some of the increase is evident among those with an English mother tongue (300.0 compared to 279.5), it is more evident among recent Australian immigrants with a foreign mother tongue (256.6 compared to 219.2). This provides suggestive evidence that Australia's broad set of immigration reforms of the late 1990s led to a better selection of foreign mother tongue migrants, at least in terms of the skills measured in the ALLS survey.

\section{INSERT FIGURE 1 HERE}

To obtain a better sense of the role of immigration policy, we next explore whether the differences in sample means are driven by differences at the bottom or top end of the skill distributions. Figure 1 plots skill percentiles for selected types of immigrants. The top-left panel reveals that the Australian distribution stochastically dominates that for Canada and the U.S. above the 20th percentile. Comparing this panel to the bottom-left panel for immigrants with a foreign mother tongue suggests that the Australian advantage in the first panel mainly reflects Australia's larger

\footnotetext{
${ }^{9}$ Among the native-born, mean document literacy scores are similar in Australia (284.2) and Canada (286.6), but considerably lower in the United States (275.0). This difference holds across all education levels, broad occupations, and age categories.
} 
share of immigrants with an English mother tongue. Below the 20th percentile in the bottom-left panel, Australian immigrants have considerably lower test scores than either Canadian or nonSpanish U.S. immigrants with a foreign mother tongue and are similar to U.S. immigrants with a Spanish mother tongue. However, beyond the 20th percentile the Australian distribution quickly converges to that of the Canadian and U.S. distributions.

Interestingly, the skill distribution for U.S. immigrants with a foreign non-Spanish mother tongue appears to dominate that of Australian immigrants in the bottom fifth of the distribution. This is consistent with the observed difference in labour market institutions between Australia and the United States. In the presence of higher minimum wages, relatively more centralized labour markets, and the existence of a welfare safety net, less skilled immigrants would prefer Australia over the United States. This is a form of immigrant self-selection resulting in the U.S. being able to attract higher skilled immigrants, relative to Australia, at the bottom end of the skill distribution. This effect might also be strengthened by a perception of greater opportunity in the U.S., together with a greater supply of unskilled jobs.

These patterns become more salient when we restrict attention to recent immigrants in the top and bottom-right panels of Figure 1. There is little difference above the median in the skills of similar immigrants to Australia, Canada, and the U.S., particularly when we restrict attention to immigrants with a foreign non-Spanish mother tongue. However, between the 10th and 50th percentiles, the Australian distribution clearly dominates. This suggests that Australia's broad menu of immigration reforms of the late 1990s served almost exclusively to raise skill levels between the 10th and 50th percentiles. We attribute this to two factors. First, going back to at least the early 1990s, roughly 10 percent of new immigrants to Australia (and Canada and the U.S.) were admitted as refugees. Since the admission criteria for refugees are unrelated to skill, it is not surprising that the immigration reforms of the late 1990s did nothing to raise skill levels below the 10th percentile, where refugees are concentrated. Second, beyond the median, where these minimum thresholds are less likely to be binding, there is little difference across the three destination countries.

The results, presented in Figure 1 provide only suggestive evidence that Australia's immigration reforms of the late 1990s led to a better selection of migrants, since differences in skills of immigrants who are within their first 10 years of arrival reflects both the skills of immigrants at the time of their arrival, as well as the accumulation of literacy skills during their first 10 years of residence in the host country. Measured literacy skills are (potentially) affected by incentives to invest in language skills following immigration which are themselves functions of domestic labour market institutions. We are able to provide two pieces of evidence to support our hypothesis that improvements in the skill of recent immigrants are more likely driven by Australia's immigration reforms than by 
greater post-migration human capital investments. First, the results in the following subsection do not indicate a higher return to skill for recent Australian immigrants. This does not suggest that there are greater incentives in Australia to invest in post-migration language skills. Of course, these post-migration investments might be greater in Australia not because of a greater return to these investments, but rather because the cost of these investments is lower. Although the data do not provide any direct information on the cost of investments in language training, it does contain some information on the incidence of training. In all three countries the data provide information on whether the respondent undertook any education or training in the previous 12 months. For the native born, the incidence of training is remarkably similar in all three countries: $55.7 \%$ in Australia, 55.3\% in Canada, and 59.4\% in the United States. There is similarly little difference in the incidence of training among recent immigrants with a foreign non-Spanish mother tongue: $55.4 \%$ in Australia, compared to $53.5 \%$ in the U.S. and $52.4 \%$ in Canada. This suggests that the incidence of post-migration human capital investments is not significantly larger in Australia, compared to Canada or the United States.

\section{INSERT FIGURE 2 HERE}

It is possible that the similarity in mean immigrant skills across destination countries arises from averaging skill distributions across a diverse set of source countries. While the source country distributions might be roughly similar across the three destinations countries, it is still possible that there are important differences within source countries, reflecting immigrant self-selection, differences in labour market institutions, as well as immigrant selection and settlement policies in the destination countries. In order to examine this possibility we restrict attention to immigrants from China - the biggest source country in the non-Spanish group. ${ }^{10}$ Proceeding cautiously in the presence of relatively small sample sizes, the resulting skill distributions in Figure 2, once again, offer little evidence that skills of U.S. immigrants dominate those of Australian or Canadian immigrants above the median. There is, however, some evidence that, relative to Australia, and to a lesser extent Canada, the U.S. is able to attract higher-quality Chinese immigrants at lower levels of measured skill. As noted above, this result is entirely consistent with the differences in labour market institutions between destination countries, as well as the relatively more generous welfare safety net provided by Australia.

Overall, the evidence suggests there is little to distinguish the literacy skills of immigrants with

\footnotetext{
${ }^{10}$ Note that the Australian sample does not provide sufficient detail to be able to identify immigrants with a Chinese mother tongue. Consequently, for the Australian sample, immigrants with a Chinese mother tongue are identified using information on country of birth. As a result, the classification for Canada and the U.S. is broader, as it includes immigrants from other Asian nations, such as Malaysia, Laos, and Vietnam, who have a Chinese mother tongue.
} 
a foreign mother tongue in Australia and Canada to U.S. immigrants with a foreign mother tongue that is not Spanish. Moreover, this result not only holds at the mean but across most of the distribution of skills. This result is consistent with the conclusions of Antecol, Cobb-Clark and Trejo (2003) based upon education and income measures in Census data. However, our results also point to higher immigrant skills in the lower end of the Australian skill distribution among recent arrivals who were subject to a broad menu of reforms to immigration selection and settlement policy in the late 1990s.

\subsection{Log Wage Returns to Immigrant Literacy Skills}

In competitive labour markets workers receive wage rates equal to the marginal productivity of their jobs, which depends on both the skills of the worker and the mix of other productive inputs employed in the job. Consequently, the marginal influence of measured skill on wage rates should be similar across workers employed in similar jobs. However, non-competitive factors, such as discrimination in hiring or credential recognition issues, can result in an under-utilization of immigrant skills, driving a wedge between the returns of immigrant and native-born workers.

To obtain evidence on the relative utilization of immigrant skills in Australia, Canada, and the U.S., we estimate the following reduced-form specification:

$$
\ln w_{i}=\beta_{0}+\beta_{S} S_{i}+\beta_{M} M_{i}+\beta_{M S}\left\{M_{i} * S_{i}\right\}+\mathbf{X}_{i} \beta_{\mathbf{X}}+\varepsilon_{i}
$$

where $\ln w_{i}$ represents the natural logarithm of hourly earnings in the main job held in the previous twelve months; $M_{i}$ is a dummy variable indicating that individual $i$ is foreign-born; $S_{i}$ is the ALLS measure of document literacy; $\mathbf{X}_{i}$ is a vector of characteristics of individual $i$ that includes a quadratic in age, controls for geographical region of residence, urban/rural area of residence, and an indicator for gender; and $\varepsilon_{i}$ is a random error component with mean zero and variance that varies across individuals. ${ }^{11}$

Differences in the return to measured skills for the native-born in Australia, Canada, and the U.S., will be reflected in differences in the estimates of $\beta_{S}$ across destination countries. Similarly, differences in the returns to immigrant skills will be reflected in differences in the estimates of $\left(\beta_{S}+\beta_{M S}\right)$ across countries. In order to simplify the interpretation of the estimates, the literacy measure has been divided by a factor of 10 and scaled to represent the difference in the score from

\footnotetext{
${ }^{11}$ The sample we use to estimate equation (1) includes all individuals that worked at least one hour in the last year. The estimated relative immigrant returns to skill could reflect hours variation if: (i) hourly wages are increasing in hours of work; (ii) hours vary systematically with skill; and (iii) preferences for work vary between natives and non-Spanish immigrants. However, it turns out that including controls for weekly hours of work in the wage equation (1) has a negligible effect upon the estimated relative returns to skill.
} 
225. ${ }^{12}$ Similarly, age has been scaled to measure years above 30 years. Consequently, the intercept term represents the mean log wage for a 30 year-old native-born male, with an assessed literacy score of 225, residing in some urban reference region (New South Wales for Australia, Ontario for Canada, and the North-East for the U.S.), whereas the estimated coefficient on the immigrant dummy represents the immigrant-native born difference in the mean log wage for an individual with an assessed literacy score of 225 and some common set of $\mathbf{X}_{i}$ characteristics.

A complication in estimating the measured skill returns in equation (1) is whether to condition on educational attainment. On the one hand, education can be viewed as an input into the production of the skills captured in the ALLS data test scores, in which case we would not want to control for education in estimating the returns to skill. On the other hand, one could argue that the estimated returns to measured skill also capture labour market returns to other skills correlated with measured literacy skills, including cognitive skills not directly assessed in the ALLS data, as well as non-cognitive skills. If the correlation between measured and unmeasured skills is different for immigrants than natives, this will show up as differential returns to skill (that is, nonzero estimates of $\beta_{M S}$ ), even in the absence of differences in skill utilization. However, to the extent that education captures these other skills, perhaps again because it is an input in producing them, conditioning on education is more likely to produce estimates of $\beta_{M S}$ that reflect differences in skill utilization. Since we are ultimately agnostic to the role of education, we have also examined a separate set of estimates that control for three broad education groups (high school or less, some post-secondary, and university degree). Although including education controls substantially reduces the estimated skill returns in all countries, none of our main findings regarding the relative return to immigrant skills are affected by their inclusion. ${ }^{13}$

\section{INSERT TABLE 4 HERE}

Table 4 presents ordinary least squares (OLS) estimates of equation (1). Similar to Figures 1 and 2, average returns to skill are estimated for the full sample of all immigrants within each destination country, as well for: (i) all recent immigrants (within 10 years of arrival); and (ii) recent immigrants with a foreign (and non-Spanish in the U.S. case) mother tongue. This is done by estimating three separate regressions, which rather than including an overall $M_{i}$ dummy, include increasing numbers of immigrant indicators distinguishing between immigrant types. ${ }^{14}$ In each

\footnotetext{
${ }^{12} \mathrm{~A}$ skill score of 225 is regarded by the survey developers as the "minimum required for individuals to meet the complex demands of everyday life and work in the emerging knowledge-based economy" (Statistics Canada 2005, p.35). Accordingly, individuals with a skill score below 225 would be deemed as functionally illiterate.

${ }^{13}$ These results are available from the authors upon request.

${ }^{14}$ Due to limited immigrant sample sizes, particularly in the U.S. sample, we are forced to restrict the coefficients on the conditioning vector $\mathbf{X}_{i}$ to be the same for immigrants and natives.
} 
case, we also report the unconditional (on measured skill) immigrant wage gaps, in order provide an indication of the relative importance of literacy skills in driving immigrant wage gaps across the three destination countries.

Looking first at the estimated immigrant wage gaps that do not condition on measured skill (but do condition on $\mathbf{X}_{i}$ ), mean log wages across all immigrants are $6 \log$ points lower in Australia; $23 \log$ points lower in Canada; and 18 log points lower in the United States. Interestingly, the substantially larger gaps in Canada and the U.S., relative to Australia, appear consistent with their larger gaps in mean immigrant skills (relative to natives) identified in Table 3. However, when we restrict attention to recent immigrants, the wage gaps in Australia and Canada increase, while in the U.S. it decreases, such that the U.S. gap is roughly similar to Australia (14 log points compared to 9), but much larger in Canada (36 log points). These results appear somewhat inconsistent with the changes in mean skills of recent immigrants, where large gains in Australia, but little change in either Canada or the U.S., would suggest a falling wage gap in Australia and little change in Canada or the United States. Of course, after conditioning on skill, these gaps will also reflect differences in returns to immigrants' skills across countries. Much larger wage gaps for recent immigrants in Canada, relative to the U.S., despite a similar difference in mean skills, would thereby suggest a relative under-utilization of immigrant skills in Canada.

As noted above, differences in mean immigrant skills across destination countries largely disappear when we restrict attention to recent immigrants with a foreign mother tongue. However, the third set of results in Table 4 reveal remarkably different unconditional (on skill) wage gaps across destination countries for this group of immigrants. In Australia, the gap is roughly twice as large as the gap among all recent immigrants (19 log points compared to 9), while in Canada it is almost unchanged (40 log points compared to 36). However, in the U.S. the wage gap is essentially zero. Of course, part of the explanation for these differences is that the mean skill of the native-born benchmark is substantially lower in the U.S. than in Australia or Canada. Regardless, these large differences in mean wage gaps in a sample of immigrants with virtually identical average measured skills, once again, appears consistent with our expectation of superior immigrant skill utilization in U.S. labour markets.

To obtain more direct evidence on skill utilization, we next turn to the estimated returns to document literacy in Table 4. First to note is that there is considerable variation in returns for the native-born across the three countries. A ten-point increase in document literacy is associated with a log wage increase of 3.1 log points in Australia, $3.4 \log$ points in Canada, and 4.1 log points in the United States. These differences appear broadly consistent with differences in labour market institutions across countries. Although, Australia experienced significant labour market deregu- 
lation in the 1990s, most notably the dismantling of its award system for wage standardization across sectors of the national economy, the labour market in Australia is still relatively regulated compared to Canada and the United States. For example, using 2006 OECD data, the ratio of the minimum wage to median wages for full-time workers was 0.54 in Australia, 0.40 in Canada, and 0.33 in the United States. Similarly, the OECD's index of the strictness of employment protection for individual and collective dismissals, was 1.42 for Australia, 0.92 for Canada, and 0.26 for the U.S. in 2006. The ranking of the estimated returns to measured skill across the three countries is also consistent with lower estimated returns to skill in countries with higher union density, stricter employment protection legislation, and larger public sectors (Hanushek at al. 2013).

Turning to the relative immigrant returns to skill in the second row of Table 4, the point estimates for Australia and Canada are both small, relative to the overall returns in the first row, and not statistically different from zero. Equivalent returns to skill for immigrant and native-born workers in Australia and Canada suggest that the unconditional wage gaps among immigrants reflect something other than an under-utilization of their skills. In Australia, the immigrant intercept is now also no longer negative, indicating that the unconditional wage gap is entirely explained by lower mean immigrant skills. In Canada, on the other hand, a wage gap of 10 log points persists across the skill distribution, the source of which is unclear, but is consistent with, for example, a concentration of immigrants within low-wage firms (Aydemir and Skuterud 2008) or even employer tastes for discrimination that are independent of skill.

The U.S. results in Table 4 appear even less consistent with an under-utilization of immigrant skills, as the return to measured skill for U.S. immigrants exceeds the already-large return for U.S. natives. Specifically, a 10-point increase in measured document literacy is associated with a $5.6 \log$ point increase for U.S. immigrants, compared to a 4.1 log point increase for U.S. natives, a difference that is statistically significant at the $10 \%$ significance level. Given the negligible coefficient on the immigrant dummy, the results imply an immigrant wage advantage (conditional on $\mathbf{X}_{i}$ ) above a skill level of 225, which is roughly the 40th percentile of the U.S. immigrant skill distribution. This is starkly different from the Canadian results, where immigrant wage disparities are evident across the entire skill distribution.

What explains a higher return to literacy skills for U.S. immigrants? One possibility is that the ALLS measure of literacy is correlated with latent productivity characteristics and the return to these characteristics is higher for immigrants. But, since immigrants interact with the same labour market institutions as natives, it is difficult to isolate a mechanism that could generate this difference in returns. Another possibility is that the covariance between measured literacy and latent productive characteristics is exceptionally high for U.S. immigrants. Although there is no 
way to rule out this possibility, we are suspicious for two reasons. First, the result is evident even when education controls, which might be expected to capture some of this latent productivity, are included (although the difference in the immigrant return is estimated less precisely). ${ }^{15}$ Second, if U.S. immigrants are exceptional on other skill dimensions, it is difficult to explain why it does not provide them with an advantage in their literacy test scores. One would have to argue that the productive characteristics that give rise to the exceptional relative wage performance of U.S. immigrants are independent of the skills captured in the ALLS data.

There is, however, an explanation for the U.S. results that does not appeal to unobservable skills of of U.S. immigrants. While it may be reasonable to interpret literacy scores of native-born workers as cognitive skills, for immigrants with a foreign mother tongue the test scores in the ALLS data will reflect a combination of English-language ability (or French in the Canadian data) and cognitive skills. To see the consequences of this measurement issue for the estimated return to skill for immigrants, consider the following model of wage determination:

$$
\ln w_{i}=\alpha_{0}+\alpha_{C} C_{i}+\alpha_{C L} C_{i}\left(L_{i}-\bar{L}\right)+v_{i}
$$

where $C_{i}$ denotes cognitive skills and $L_{i}$ denotes language ability, where $L_{i} \in[0, \bar{L}]$. The lower bound of zero denotes the minimum language requirement in the job that requires the least language ability. Note that $\left(L_{i}-\bar{L}\right)<0$ so language ability deficits reduce wages. Assume that all nativeborn workers have the maximum language ability of $\bar{L} .^{16}$ A marginal improvement in cognitive skills for immigrants has a direct effect on wages through $\alpha_{C}$, as well as an additional effect that depends on the size of the language deficit. The logic is that in many production processes, implementation of cognitive skills requires communication skills. This idea is consistent with the evidence of Berman, Lang and Siniver (2003) showing wage returns to Hebrew-language acquisition among Israeli immigrants employed in high-skill, but not low-skill, occupations.

Suppose also that measured skill in the ALLS data is additive in cognitive skills and language abilities, such that:

$$
S_{i}=C_{i}+\left(L_{i}-\bar{L}\right)
$$

For native-born workers, with $L_{i}=\bar{L}$, measured skills directly measure cognitive skills. For immigrant workers, their skill score will be less than their 'true' cognitive ability due to language deficiencies and cultural distance. Without loss of generality, consider the extreme case that all immigrants have the same level of cognitive skill $\bar{C}_{M}$, such that all of the variation in immigrants'

\footnotetext{
${ }^{15}$ Specifically, the immigrant return to a 10 -point increase in literacy is 3.6 log points, compared to 2.5 log points for natives. The p-value on this difference is 0.201 .

${ }^{16}$ Note that language only affects wages through its 'complementarity' with cognitive skills. An independent return to language, say $\alpha_{L}$, would imply a value of language even in the absence of any cognitive skills, which seems implausible.
} 
measured skills reflect variation in language skills. In this case, native and immigrant wages will be determined by:

$$
\ln w_{i}= \begin{cases}\alpha_{0}+\alpha_{C} S_{i}+v_{i} & \text { if native-born } \\ \alpha_{0}+\alpha_{C} \bar{C}_{M}+\alpha_{C L} \bar{C}_{M}\left(S_{i}-\bar{C}_{M}\right)+v_{i} & \text { if immigrant }\end{cases}
$$

such that the return to measured skills $S_{i}$ is given by $\alpha_{C}$ for the native-born and $\alpha_{C L} \bar{C}_{M}$ for immigrants. Provided $\alpha_{C L} \bar{C}_{M}>\alpha_{C}$, the immigrant return to skill will exceed the native-born return to skill. ${ }^{17}$

In countries where labour market institutions do more to standardize wages, such as Australia, and to a lesser extent Canada, both the economy-wide return to skill $\left(\alpha_{C}\right)$ and the attenuating effect of language on this complementary return $\left(\alpha_{C M}\right)$ will tend to be small. Hence, their difference will be small. In the U.S., on the other hand, where the return to skill is large, the attenuating effect of language will also tend to be large. Consequently, it becomes more likely that marginal improvements in language ability produce big wage gains. As suggestive evidence of this alternative explanation, the return to measured skill for U.S. immigrants becomes even larger when it is estimated separately for recent U.S. immigrants with a foreign mother tongue (that is not Spanish). The third set of estimates in Table 4 suggest that a 10-point increase in literacy is associated with a $6.8(0.041+0.027) \log$ point increase in wages of recent non-English/non-Spanish U.S. immigrants, compared to a $4.1 \mathrm{log}$ point increase for U.S. natives (the p-value for the difference of 0.027 is 0.057). The comparable estimates for recent Canadian immigrants with a foreign mother continue to suggest essentially no difference in the return to immigrant skill, although the immigrant intercept continues to point to a large (23 log points in the case of recent immigrants with a foreign mother tongue) wage disparity across the entire skill distribution. For Australia, on the other hand, there is, if anything, some evidence of a lower return to immigrant skills when we restrict attention to recent immigrants with a foreign mother tongue. We interpret this as suggestive evidence that Australia's broad menu of immigration reforms of the late 1990s did not result in a greater utilization of immigrant skills.

Finally, it is worth noting that the estimates in Table 4 suggest that recent U.S. immigrants with a Spanish mother tongue, receive substantially lower returns to skill than their native-born counterparts. This result is in sharp contrast to the estimates for other U.S. immigrants with a foreign mother tongue, who receive significantly higher skill returns than natives. What explains this difference? To understand it, one must keep in mind that the skill distribution of recent Spanish immigrants in the U.S. lies substantially below that of other U.S. immigrants with a foreign mother

\footnotetext{
${ }^{17}$ Note that this result requires that cognitive skills $C_{i}$ and language abilities $L_{i}$ are more complementary in wage determination than in the production of test scores. In the example, we present the extreme case in which $C_{i}$ and $L_{i}$ are multiplicative in wage determination, but additively separable in test score outcomes.
} 
tongue. Specifically, roughly three-quarters of recent Spanish immigrants have a skill score below the intercept value of 225, compared to one-quarter of other foreign mother tongue immigrants. The lower marginal return to skill for Spanish immigrants means that a decrease in skill below 225 reduces the immigrant wage gap. With an immigrant intercept of -14.9 log points, the gap in the immigrant return of 2.9 log points implies no wage differential for Spanish immigrants at a skill level of 175 and a wage advantage below 175, which is roughly $40 \%$ of all recent Spanishspeaking U.S. immigrants. ${ }^{18}$ But at these extremely low measured skill levels, there is essentially no labour market competition from native-born workers (this is the 3rd percentile of the native-born population distribution, including those not participating in labour markets). Consequently, their relative wages are high, but as the skill level of jobs increases, there is increasing competition from U.S. workers with comparable skills. If for some reason Spanish workers are unable to compete, if for example they experience discrimination in more skilled labour markets, we would expect wage gaps conditional on skill, which is precisely what appears in the estimates.

\subsection{Further Evidence on Skill Utilization}

Given the difficulty in distinguishing returns to language abilities from returns to other skills, we cannot rule out the possibility that the higher return to literacy skills for U.S. immigrants reflect, at least in part, more efficient skill utilization, perhaps resulting from a greater role of employers in immigrant selection. To obtain further evidence on this possibility we first examined whether the higher wage return to literacy for U.S. immigrants reflects better access to higher paying occupations by exploiting the Occupational Information Network (O*NET) database. To do so we extracted 12 descriptors of document literacy in the $\mathrm{O}^{*} \mathrm{NET}$ database and used a principal component analysis, weighting observations by U.S. occupational employment levels, to reduce these descriptors to a single factor. We then linked this single factor to the 4-digit International Standard Classification of Occupations (ISCO88) codes provided in the ALLS data using a crosswalk with the Standard Occupational Classification codes used by the O*NET. Finally, we standardized the single factor, such that it had a weighted mean of 225 and standard deviation of 50 in the weighted sample, thereby making our required document literacy score, based on $\mathrm{O}^{*} \mathrm{NET}$ data, roughly comparable to the measured document literacy score in the ALLS data. Four-digit occupation codes were, unfortunately, not available for the Australian ALLS data, so this analysis was only possible with

\footnotetext{
${ }^{18}$ To see this, note that the immigrant intercept implies a wage gap of 14.9 log points at a skill level of 225 . The immigrant-specific return of -0.029 means that reducing skill by 10 points serves to reduce this gap by 2.9 log points, so that it is $12 \log$ points at a skill level of 215 . Hence, the gap will be zero at a skill level $225-(0.149 / 0.029) * 10)=174$.
} 
the Canadian and U.S. data. ${ }^{19}$

\section{INSERT TABLE 5 HERE}

In Table 5 we report the results from estimating equation (1) when we use our measure of the required document literacy of individual i's 4-digit occupation as the dependent variable. Comparing the unconditional (on measured literacy) immigrant gaps in required literacy, the results point to an almost identical disparity of roughly of 15 points for Canadian and U.S. immigrants. When we condition on measured literacy, the returns for native-born workers in Canada and the U.S. are also almost identical, suggesting that a 10-point increase in the ALLS literacy test score is associated with an increase of roughly 3.5 points in required occupational literacy. Under-utilization of immigrant skills would imply a lower return to measured literacy for immigrants. However, in both Canada and the U.S. the returns are significantly larger for immigrants. Specifically, a 10-point increase in measured literacy is associated with an increase of $4.6(3.528+1.078)$ and 5.3 points $(3.631+1.698)$ in the required literacy of Canadian and U.S. immigrants' occupations, respectively. Once again, these results do not suggest that immigrant skills are under-utilized across occupations in Canada or more efficiently utilized across occupations in the United States. However, note that we cannot make any conclusions regarding the utilization of immigrant skill within occupations.

Estimating these effects separately for recent immigrants and recent immigrants with a foreign mother tongue does essentially nothing to change the findings. The estimates continue to suggest that marginal improvements in literacy skills do more to boost the occupational attainment of immigrants than natives. The sole exception is, once again, U.S. immigrants with a Spanish mother tongue, whom appear to be highly concentrated in exceptionally low-skill labour markets where returns to skill are low. What explains the high returns for Canadian immigrants with a nonEnglish/French mother tongue and U.S. immigrants with a non-English/Spanish mother tongue? Our suspicion is that what underlies these returns is, once again, that marginal improvements in immigrant literacy skills in large part reflect differences in language abilities, which are complementary with other skills, much of which may have been obtained in immigrants' source countries. To the extent that this interpretation is correct, the large immigrant returns to measured literacy in Table 5 suggest that language acquisition benefits immigrants by enabling them to make transitions

\footnotetext{
${ }^{19}$ We used the 12 level descriptors identified by LaPolice, Carter and Johnson (2008, Table 9) as relevant for document literacy. They included 3 abilities (written comprehension; deductive reasoning; and information ordering); 3 skills (writing; active learning; and judgement and decision making); one knowledge (English language); and 5 work activities (getting information needed to do the job; processing information; scheduling work and activities; organizing, planning, and prioritizing work; and documenting and recording information. To collapse 6-digit occupation codes in the $\mathrm{O}^{*} \mathrm{NET}$ down to 4-digit SOC2000 codes, we took unweighted averages of each of the 12 descriptors. To collapse the 12 descriptors down to a single factor, we used principal component analysis weighting observations by occupational employment levels for the U.S. in 2005. Also, in some cases there were multiple SOC2000 codes for a single ISCO 88 code. In these cases., we took the average of the SOC2000 codes weighted by their employment levels.
} 
to occupations that are more commensurate with their skills.

In addition, to examining the literacy requirements of immigrants' occupations, we also investigate the possibility that under-utilization of immigrant skills occurs through access to jobs, rather than through wage rates or occupational attainment. To do this, we estimated equation (1) replacing log wages with two alternative binary indicators of employment. In the first case, we include both labour market participants and non-participants and define individuals as employed if they held a job at any time in the previous twelve months. Since some of this variation is likely to reflect labour supply decisions, that are likely themselves correlated with literacy skills, we also estimate the model restricting attention to labour market participants and defining employment as working positive hours for pay in the survey reference week. While this variable gets closer to a measure of involuntary unemployment, there are some concerns about its consistency across the three countries. Specifically, in the Australian survey, unemployment is defined according to the international definition, which classifies an individual as unemployed if: (i) they are not employed; (ii) had actively searched for work at any time in the four weeks up to the end of the reference week; and (iii) were available for work in the reference week if they had found a job. However, in the Canadian and U.S. versions of the survey there is no indication that the reporting of unemployment requires active job search in the previous four weeks or availability for work. ${ }^{20}$

Given the binary dependent variable, which has a sample mean above 0.9 when we restrict attention to labour force participants, our preference is to estimate equation (1) using a probit model. This, however, makes the interpretation of the marginal effects of skill across the distribution more complicated. Therefore, rather than present the estimates in tables, in Figures 3 and 4 we plot the difference in the predicted employment or unemployment rate between a 30-year-old male immigrant residing in some reference urban region and his native-born counterpart. ${ }^{21}$

\section{INSERT FIGURE 3 HERE}

The results in Figure 3 once again provide essentially no evidence of skill under-utilization, most notably in Australia, where we expect regulated labour markets to make the access to employment margin more relevant. Whether looking across all immigrants or recent immigrants with a foreign mother tongue, there is no indication of disparities in the employment rates of Australian immigrants across the skill distribution. For Canada, on the other hand, there is evidence of employment gaps among recent immigrants with a foreign mother tongue regardless of their skill level. Given

\footnotetext{
${ }^{20}$ Comparing the March 2003 Current Population Survey (CPS) with the U.S. ALLS, indicates significantly higher unemployment rates in the ALLS, particularly for the least educated native-born workers. The share of native-born workers in the least-educated group is, however, very similar in the ALLS and CPS, suggesting the difference in unemployment rates reflects measurement, as opposed to sampling, issues.

${ }^{21}$ The probit estimates underlying both figures are provided in the Appendix.
} 
the large wage gaps also facing this group, it may be that their employment shortfalls primarily reflect labour supply choices. Finally, for the U.S., there is some evidence of employment gaps among higher-skilled immigrants. The gaps appear much larger for Spanish immigrants, although one must keep in mind that predictions for this group beyond a skill level of 225 are essentially out of sample.

\section{INSERT FIGURE 4 HERE}

Restricting the sample to labour force participants in Figure 4 suggests that the employment rate gaps of non-Spanish U.S. immigrants with a foreign mother tongue do, indeed, reflect labour supply choices, as the bottom two panels provide no evidence of higher unemployment rates for this group. The results continue, however, to point to employment challenges for recent Canadian immigrants with a foreign mother tongue. Although the gap in unemployment rates for this group appears to grow slightly with literacy, the difference in the slope parameter is poorly identified and not statistically significant. Lastly, there continues to be no real evidence that Australian immigrants face challenges accessing jobs, relative to their native-born counterparts with similar skills. Overall, our findings contrast to some extent with the current literature, as we find little evidence of a tradeoff in assimilation between prices and quantities (Antecol, Kuhn and Trejo 2006). Rather, in Australia and the U.S., where wage gaps for immigrants are either small or non-existent (once we condition on literacy skills), we find little evidence of employment shortfalls. In Canada, on the other hand, where there is evidence of substantial wage gaps across the skill distribution, we do find evidence of pervasive employment gaps.

\section{Conclusions}

The main finding of our analysis is that there is little to distinguish the skills of Australian and Canadian immigrants with a foreign mother tongue and U.S. immigrants with a non-Spanish foreign mother tongue. This result holds not only at the mean, but across most of the entire distribution of skills. However, we also find suggestive evidence that a broad menu of reforms to Australian immigrant selection and settlement policy in the late 1990s was successful in raising immigrant skill levels in the middle of the skill distribution where these reforms are more likely to be binding. Unfortunately, our data prevent us from making firm conclusions on whether these gains reflect the selection of better quality immigrants within source countries or from endogenous responses in the country of origin distribution, as emphasized by Clarke and Skuterud (2013).

Examining relative returns to immigrant literacy skills, we find no compelling evidence that providing employers with a greater role in immigrant selection leads to greater immigrant skill 
utilization. Although wage returns to immigrant literacy skills appear exceptionally large in the U.S., where employers have played a larger role in immigrant selection, our reading of the evidence is that they reflect complementarities between language and skills. Most notably, our findings relating measures of required literacy skills of immigrants' occupations, obtained from the $\mathrm{O}^{*} \mathrm{NET}$ database, to their measured literacy skills in the ALLS data, suggest little difference in the relative utilization of immigrant skills across occupations in Canada and the United States.

There is a presumption in much of the Canadian policy discourse that wage and employment disparities of recent immigrants reflect an under-utilization of immigrant skills owing primarily to credential recognition issues. Our results based on wage and employment returns to literacy skills, as well as the skill requirements of immigrants' occupations, are not consistent with this view. Rather, we find that the labour market challenges facing recent immigrants to Canada with a foreign mother tongue are substantial in comparison to their Australian and U.S. counterparts, both in terms of wage outcomes and employment probabilities, and are pervasive across the skill distribution. These gaps are beyond the scope of this paper to explain. However, a possible explanation is that they reflect sorting of immigrants across employers in Canada (Aydemir and Skuterud 2008; Pendakur and Woodcock 2010). A comparative analysis of immigrant sorting across employers for Australia and the U.S. would appear to be a potentially fruitful area for future research. 


\section{Acknowledgements}

This paper was completed while Andrew Clarke was a visiting scholar in the Office of Population Research, Princeton University. Their hospitality, and in particular the generous hospitality of Marta Tienda, is gratefully acknowledged. Mikal Skuterud acknowledges financial support from the Social Science and Humanities Research Council of Canada (No. 410-2011-0281). We thank the Editor of this journal and two anonymous referees for their numerous helpful comments. 


\section{References}

Antecol, Heather, Deborah Cobb-Clark, and Stephen Trejo (2003), "Immigration Policy and the Skills of Immigrants to Australia, Canada, and the United States", Journal of Human Resources 38(1): 192-218.

Antecol, Heather, Peter Kuhn, and Stephen Trejo (2006), "Assimilation via Prices or Quantities: Sources of Immigrant Earnings Growth in Australia, Canada, and the United States", Journal of Human Resources 41(4): 821-40.

Aydemir, Abdurrahman and Mikal Skuterud (2005), "Explaining the Deteriorating Entry Earnings of Canadas Immigrant Cohorts: 1966-2000", Canadian Journal of Economics 38(2): 641-671.

Aydemir, Abdurrahman and Mikal Skuterud (2008), "The Immigrant Wage Differential Within and Across Establishments", Industrial and Labor Relations Review 61(3): 334-52.

Aydemir, Abdurrahman (2014), "Skill-Based Immigration, Economic Integration, and Economic Performance," IZA: World of Labour 41.

Barrett, Garry (2012), "The Return to Cognitive Skills in the Australian Labour Market", Economic Record 88(280): 1-17.

Berman, Eli, Kevin Lang and Erez Siniver (2003), "Language-skill complementarity: returns to immigrant language acquisition", Labour Economics 10: 265-290.

Blau, Francine D. and Lawrence Kahn (2005), "Do Cognitive Test Scores Explain Higher U.S. Wage Inequality?", Review of Economics and Statistics 87(1): 184-93.

Borjas, George J (1987), "Self-Selection and the Earnings of Immigrants", American Economic Review 77(4): 531-553.

Bratsberg, Bernt, Torbjørn Hægeland, and Oddbjørn Raaum (2013), "Immigrant Skills and Employment: Cross Country Evidence from the Adult Literacy and Life Skills Survey", Statistics Norway Research Department Discussion Paper, No. 730

Clarke, Andrew J. and Skuterud, Mikal (2013), "Why do Immigrant Workers in Australia Perform Better than those in Canada? Is the Immigrants or their Labour Markets", Canadian Journal of Economics 46(4): 1431-1462 
Cobb-Clark, Deborah A. (2003), "Public Policy and the Labor Market Adjustment of New Immigrants to Australia", Journal of Population Economics 16: 655-681

Dechief, Diane and Philip Oreopoulos (2012), "Why Do Some Employers Prefer To Interview Matthew, but not Samir? New Evidence From Toronto, Montreal and Vancouver", CLSRN Working Paper, No.95.

Ferrer, Ana, David A. Green and W. Craig Riddell (2006), "The Effect of Literacy on Immigrant Earnings", Journal of Human Resources 41(2): 380-410.

Green, David A. and W. Craig Riddell (2003), "Literacy and Earnings: An Investigation of the Interaction of Cognitive and Unobserved Skills in Earnings Generation", Labour Economics 10(2): 165-184.

Gregory, Robert G. (2014), "The Two-Step Australian Immigration Policy and its Impact on Immigrant Employment Outcomes", IZA Discussion Paper No. 8061.

Hanushek Eric A., Guido Schwerdt, Simon Wiederhold and Ludger Woessmann (2015), "Returns to Skills around the World: Evidence from PIAAC", European Economic Review 73: $103-130$

Kahn, Lawrence M, (2004), "Immigration, Skills and the Labor Market: International Evidence", Journal of Population Economics 17(3): 501-534

LaPolice Christelle, Gary W. Carter and Jeff W. Johnson (2008), "Linking O*NET Descriptors to Occupational Literacy Requirements Using Job Component Validation", Personnel Psychology 61: 404-441

Oreopoulos, Philip (2011), "Why Do Skilled Immigrants Struggle in the Labor Market", American Economic Journal: Economic Policy 3(4): 148-171.

Pendakur, Krishna and Simon Woodcock (2010), "Glass Ceilings or Glass Doors: Wage Disparity Within and Between Firms", Journal of Business and Economic Statistics 28(1): 181-189.

Richardson, Sue and Lawrence Lester (2004), "A Comparison of Australian and Canadian Immigration Policies and Labour Market Outcomes", Department of Immigration and Multicultural and Indigenous Affairs, Canberra.

Statistics Canada (2005), "Learning a Living: First Results of the Adult Literacy and Life Skills Survey", Minister of Industry , Canada and Organisation for Economic Cooperation and Development (OECD), Paris. 


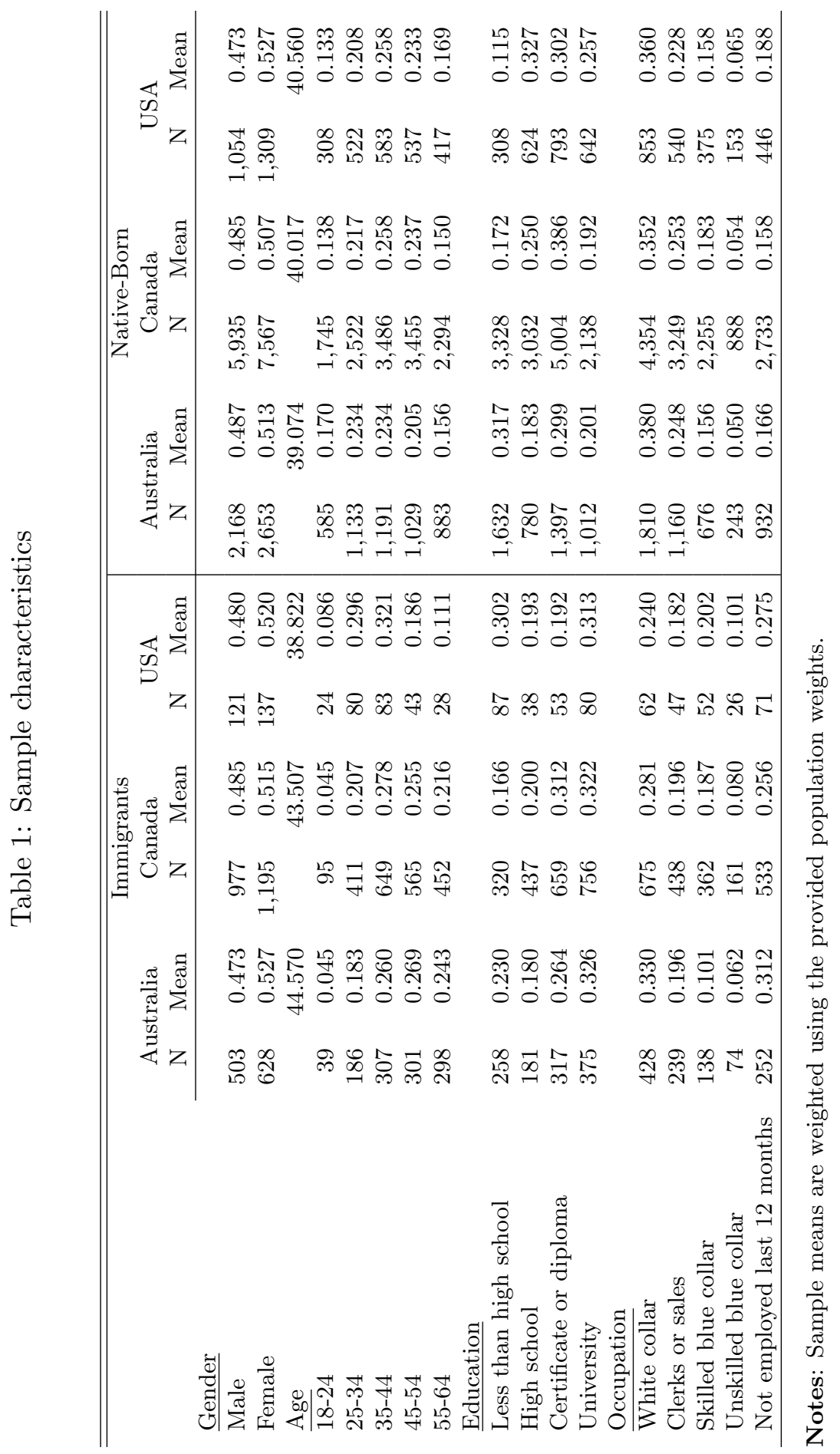


Table 2: Immigrant sample characteristics

\begin{tabular}{lrrrrrr}
\hline \hline & \multicolumn{2}{c}{ Australia } & \multicolumn{2}{c}{ Canada } & \multicolumn{2}{c}{ USA } \\
& $\mathrm{N}$ & Mean & $\mathrm{N}$ & Mean & $\mathrm{N}$ & Mean \\
\cline { 2 - 7 } Native mother tongue & 522 & 0.400 & 547 & 0.228 & 36 & 0.157 \\
Foreign mother tongue & 609 & 0.600 & 1,625 & 0.772 & & \\
Spanish mother tongue & & $\ldots$ & & $\ldots$ & 125 & 0.443 \\
Other foreign mother tongue & & $\ldots$ & & $\ldots$ & 97 & 0.400 \\
Recent immigrants & 427 & 0.389 & 1,076 & 0.440 & 111 & 0.438 \\
Recent: Native mother tongue & 175 & 0.136 & 180 & 0.076 & 15 & 0.073 \\
Recent : Foreign mother tongue & 252 & 0.253 & 896 & 0.364 & & \\
Recent: Spanish mother tongue & & $\ldots$ & & $\ldots$ & 56 & 0.201 \\
Recent: Other foreign mother tongue & & $\ldots$ & & $\ldots$ & 40 & 0.164 \\
Not recent immigrants & 704 & 0.611 & 1,096 & 0.560 & 147 & 0.562 \\
Not Recent: Native mother tongue & 347 & 0.264 & 367 & 0.152 & 21 & 0.084 \\
Not Recent : Foreign mother tongue & 357 & 0.347 & 729 & 0.408 & & \\
Not Recent: Spanish mother tongue & & $\ldots$ & & $\ldots$ & 69 & 0.242 \\
Not Recent: Other foreign mother tongue & & $\ldots$ & & $\ldots$ & 57 & 0.236 \\
\hline Total immigrants & 1,131 & 0.205 & 2,172 & 0.182 & 258 & 0.117 \\
\hline
\end{tabular}

Notes: For Australia and the United States, individuals are characterised as having a native mother tongue if English was their first language learned and currently understood. For Canada, English and French are defined as a native mother tongue. Recent immigrants are defined as foreign-born individuals that have resided in the destination country for less than 10 years. Sample means are weighted using the provided population weights. 
Table 3: Mean document literacy across selected immigrant characteristics

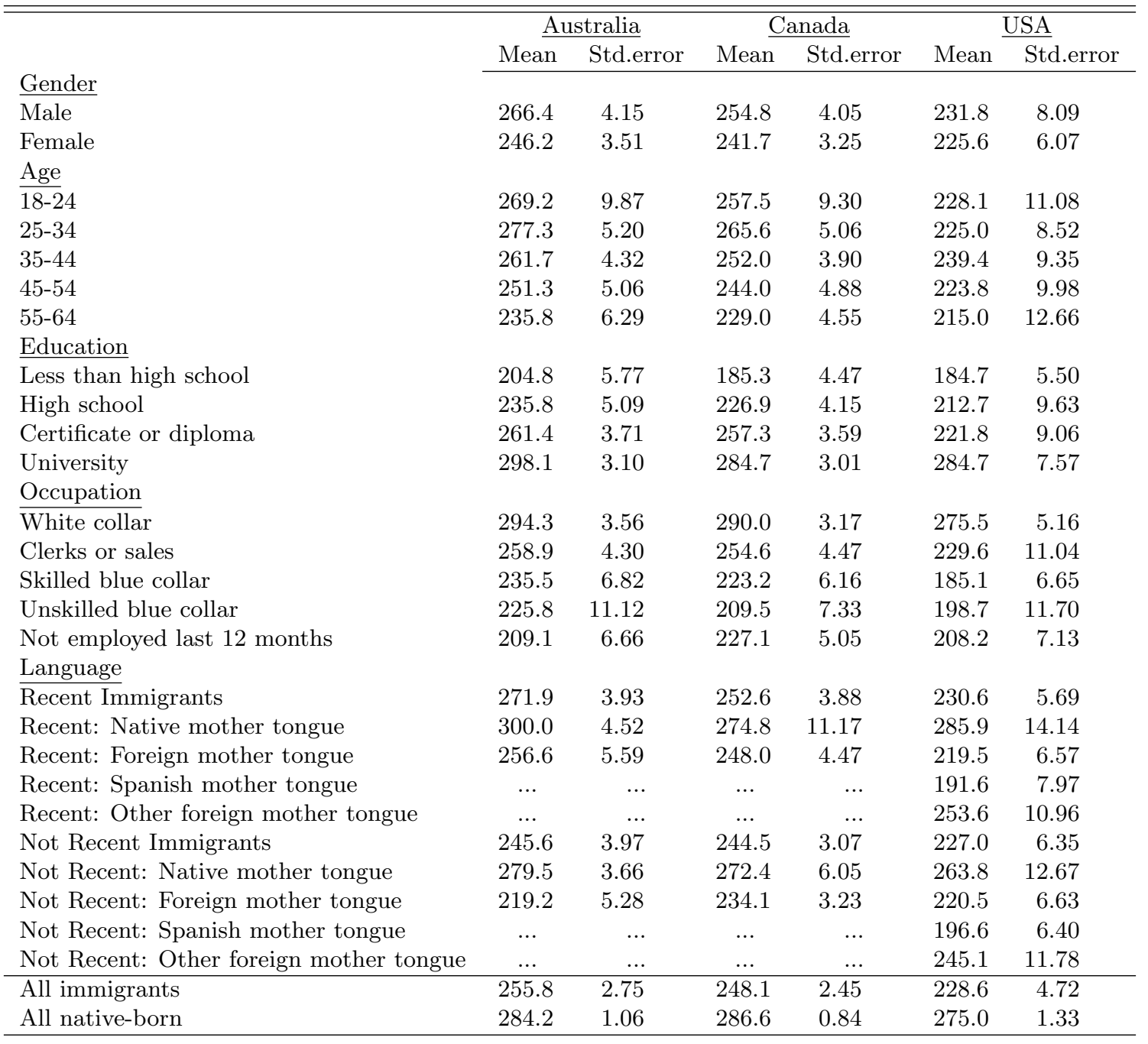

Notes: Reported means $\bar{y}$ are unweighted averages of five weighted means $\bar{y}_{j}$, each estimated separately using one of five provided plausible values and the population weights. Standard errors are estimated using $\operatorname{Var}(\bar{y})=J^{-1} \sum_{j} \operatorname{Var}\left(\bar{y}_{j}\right)+(J+1)(J(J-1))^{-1} \sum_{j}\left(\bar{y}_{j}-\bar{y}\right)$, where $\operatorname{Var}\left(\bar{y}_{j}\right)$ is estimated using the provided jackknife replicate weights and $\mathrm{J}=5$ represents the number of plausible values. 
Table 4: Immigrant log hourly wage differential conditional on document literacy level

\begin{tabular}{|c|c|c|c|c|c|c|c|c|c|}
\hline \multirow{3}{*}{ All Immiorants } & \multicolumn{3}{|c|}{ Australia } & \multicolumn{3}{|c|}{ Canada } & \multicolumn{3}{|c|}{ United States } \\
\hline & Coeff. & Std.error & $\mathrm{p}$ & Coeff. & Std.error & $\mathrm{p}$ & Coeff. & Std.error & $\mathrm{p}$ \\
\hline & & & & & & & & & \\
\hline$\frac{\text { All Immigrants }}{\text { Literacy }}$ & 0.031 & $(0.003)$ & 0.000 & 0.034 & $(0.002)$ & 0.000 & 0.041 & $(0.003)$ & 0.000 \\
\hline Literacy*Immigrant & -0.003 & $(0.004)$ & 0.551 & -0.001 & $(0.005)$ & 0.871 & 0.015 & $(0.008)$ & 0.064 \\
\hline Immigrant & 0.010 & $(0.030)$ & 0.736 & -0.097 & $(0.032)$ & 0.003 & 0.030 & $(0.062)$ & 0.634 \\
\hline Intercept & 2.937 & $(0.027)$ & 0.000 & 2.627 & $(0.025)$ & 0.000 & 2.594 & $(0.041)$ & 0.000 \\
\hline$R^{2}$ & & 0.157 & & & 0.230 & & & 0.267 & \\
\hline \multicolumn{10}{|l|}{ Unconditional Wage Gap } \\
\hline Immigrant & -0.064 & $(0.026)$ & 0.019 & -0.233 & $(0.033)$ & 0.000 & -0.175 & $(0.058)$ & 0.003 \\
\hline \multicolumn{10}{|l|}{ Recent Immigrants } \\
\hline$\overline{\text { Literacy }}$ & 0.031 & $(0.003)$ & 0.000 & 0.034 & $(0.002)$ & 0.000 & 0.041 & $(0.003)$ & 0.000 \\
\hline Literacy*Recent & -0.001 & $(0.005)$ & 0.891 & 0.000 & $(0.007)$ & 0.999 & 0.011 & $(0.013)$ & 0.371 \\
\hline Literacy*Not-recent & -0.002 & $(0.006)$ & 0.749 & 0.001 & $(0.005)$ & 0.829 & 0.019 & $(0.010)$ & 0.053 \\
\hline Recent immigrants & -0.047 & $(0.040)$ & 0.241 & -0.223 & $(0.047)$ & 0.000 & 0.044 & $(0.088)$ & 0.618 \\
\hline Not-recent immigrants & 0.043 & $(0.036)$ & 0.230 & 0.001 & $(0.036)$ & 0.981 & 0.020 & $(0.072)$ & 0.782 \\
\hline Intercept & 2.942 & $(0.028)$ & 0.000 & 2.638 & $(0.024)$ & 0.000 & 2.594 & $(0.041)$ & 0.000 \\
\hline$R^{2}$ & & 0.158 & & & 0.236 & & & 0.267 & \\
\hline \multicolumn{10}{|l|}{ Unconditional Wage Gap } \\
\hline Recent immigrants & -0.091 & $(0.037)$ & 0.017 & -0.359 & $(0.047)$ & 0.000 & -0.143 & $(0.085)$ & 0.091 \\
\hline Not-recent immigrants & -0.042 & $(0.032)$ & 0.196 & -0.125 & $(0.031)$ & 0.000 & -0.200 & $(0.070)$ & 0.005 \\
\hline \multicolumn{10}{|l|}{ Recent Immigrants with } \\
\hline \multicolumn{10}{|l|}{$\overline{\text { Foreign Mother Tongue }}$} \\
\hline$\overline{\text { Literacy }}$ & 0.031 & $(0.003)$ & 0.000 & 0.034 & $(0.002)$ & 0.000 & 0.041 & $(0.003)$ & 0.000 \\
\hline Literacy*Recent foreign & -0.009 & $(0.006)$ & 0.138 & -0.005 & $(0.008)$ & 0.510 & $\ldots$ & $\ldots$ & $\ldots$ \\
\hline Literacy*Recent Spanish & $\ldots$ & $\ldots$ & $\ldots$ & $\ldots$ & $\ldots$ & $\ldots$ & -0.029 & $(0.015)$ & 0.051 \\
\hline Literacy*Recent other foreign & $\ldots$ & $\ldots$ & $\ldots$ & $\cdots$ & $\cdots$ & $\cdots$ & 0.027 & $(0.014)$ & 0.057 \\
\hline Literacy*Not-recent foreign & -0.003 & $(0.007)$ & 0.608 & 0.002 & $(0.006)$ & 0.742 & & $\ldots$ & $\ldots$ \\
\hline Literacy*Not-recent Spanish & $\ldots$ & $\ldots$ & $\ldots$ & $\ldots$ & $\ldots$ & $\ldots$ & 0.010 & $(0.015)$ & 0.504 \\
\hline Literacy*Not-recent other foreign & $\ldots$ & $\ldots$ & $\ldots$ & $\ldots$ & $\ldots$ & $\ldots$ & 0.014 & $(0.016)$ & 0.395 \\
\hline Recent foreign & -0.070 & $(0.047)$ & 0.134 & -0.230 & $(0.050)$ & 0.000 & & & $\ldots$ \\
\hline Recent Spanish & $\ldots$ & $\ldots$ & $\ldots$ & $\ldots$ & $\ldots$ & $\ldots$ & -0.149 & $(0.097)$ & 0.125 \\
\hline Recent other foreign & $\ldots$ & $\ldots$ & $\ldots$ & $\ldots$ & $\ldots$ & $\ldots$ & 0.046 & $(0.132)$ & 0.726 \\
\hline Not-recent foreign & 0.022 & $(0.045)$ & 0.627 & -0.018 & $(0.039)$ & 0.639 & $\ldots$ & $\ldots$ & $\ldots$ \\
\hline Not-recent Spanish & $\ldots$ & $\ldots$ & $\ldots$ & $\ldots$ & $\ldots$ & $\ldots$ & -0.016 & $(0.103)$ & 0.878 \\
\hline Not-recent other foreign & $\ldots$ & $\ldots$ & $\ldots$ & $\ldots$ & $\ldots$ & $\ldots$ & 0.030 & $(0.088)$ & 0.735 \\
\hline Intercept & 2.947 & $(0.028)$ & 0.000 & 2.639 & $(0.024)$ & 0.000 & 2.594 & $(0.040)$ & 0.000 \\
\hline$R^{2}$ & & 0.160 & & & 0.237 & & & 0.270 & \\
\hline \multicolumn{10}{|l|}{ Unconditional Wage Gap } \\
\hline Recent foreign & -0.193 & $(0.047)$ & 0.000 & -0.401 & $(0.053)$ & 0.000 & $\ldots$ & & $\ldots$ \\
\hline Recent Spanish & $\ldots$ & $\ldots$ & $\ldots$ & $\ldots$ & $\ldots$ & $\ldots$ & -0.425 & $(0.067)$ & 0.000 \\
\hline Recent other foreign & $\ldots$ & $\ldots$ & $\ldots$ & $\ldots$ & $\ldots$ & $\ldots$ & 0.018 & $(0.123)$ & 0.881 \\
\hline Not-recent foreign & -0.133 & $(0.043)$ & 0.003 & -0.183 & $(0.036)$ & 0.000 & $\ldots$ & $\ldots$ & $\ldots$ \\
\hline Not-recent Spanish & $\ldots$ & $\ldots$ & $\ldots$ & $\ldots$ & $\ldots$ & $\ldots$ & -0.408 & $(0.088)$ & 0.000 \\
\hline Not-recent other foreign & $\ldots$ & $\ldots$ & $\ldots$ & $\ldots$ & $\ldots$ & $\ldots$ & -0.090 & $(0.095)$ & 0.343 \\
\hline
\end{tabular}

Notes: Reported coefficients $\bar{b}$ are unweighted averages of five ordinary least squares (OLS) estimates $\bar{b}_{j}$, each using one of the five plausible values of literacy and the population weights. Standard errors are estimated using $\operatorname{Var}(\bar{b})=J^{-1} \sum_{j} \operatorname{Var}\left(\bar{b}_{j}\right)+(J+1)(J(J-1))^{-1} \sum_{j}\left(\bar{b}_{j}-\bar{b}\right)$, where $\operatorname{Var}\left(\bar{b}_{j}\right)$ is estimated using the provided jackknife replicate weights and $\mathrm{J}=5$ represents the number of plausible values. Literacy is adjusted by subtracting 225 and dividing by 10. Regressions include a quadratic in age, controls for geographical region of residence, urban/rural area of residence, and an indicator for gender. The samples are restricted to individuals aged 18-64 who were employed in the previous 12 months. The immigrant sample is restricted to individuals who arrived in their destination country at age 14 or higher after 1955. For Australia and the United States, individuals are characterised as having a foreign mother tongue if English was not their first language learned and understood. For Canada, a foreign mother tongue is defined for first languages other than English or French. Recent immigrants refer to foreign-born individuals that have less than ten years of residence in the destination country. 
Table 5: Immigrant differential in required document literacy conditional on measured document literacy

\begin{tabular}{|c|c|c|c|c|c|c|}
\hline & \multicolumn{3}{|c|}{ Canada } & \multicolumn{3}{|c|}{ United States } \\
\hline & Coeff. & Std.error & $\mathrm{p}$ & Coeff. & Std.error & $\mathrm{p}$ \\
\hline & \multicolumn{6}{|c|}{ All Immigrants } \\
\hline$\overline{\text { Literacy }}$ & 3.528 & $(0.225)$ & 0.000 & 3.631 & $(0.208)$ & 0.000 \\
\hline Literacy*Immigrant & 1.078 & $(0.376)$ & 0.004 & 1.698 & $(0.679)$ & 0.013 \\
\hline Immigrant & -4.098 & $(2.716)$ & 0.131 & 2.403 & $(3.708)$ & 0.517 \\
\hline Intercept & 220.655 & $(2.775)$ & 0.000 & 230.910 & $(2.951)$ & 0.000 \\
\hline$R^{2}$ & & 0.201 & & & 0.223 & \\
\hline \multicolumn{7}{|l|}{ Unconditional Gap } \\
\hline $\begin{array}{l}\text { Immigrant } \\
\text { Recent Immigrants }\end{array}$ & -14.609 & $(2.952)$ & 0.000 & -15.286 & $(4.455)$ & 0.002 \\
\hline Literacy & 3.543 & $(0.225)$ & 0.000 & 3.632 & $(0.208)$ & 0.000 \\
\hline Literacy*Recent & 1.157 & $(0.614)$ & 0.060 & 1.693 & $(1.146)$ & 0.140 \\
\hline Literacy*Not Recent & 0.942 & $(0.445)$ & 0.035 & 1.744 & $(0.741)$ & 0.019 \\
\hline Recent Immigrants & -0.339 & $(3.404)$ & 0.921 & 0.800 & $(6.470)$ & 0.902 \\
\hline Not Recent Immigrants & -7.135 & $(3.434)$ & 0.038 & 3.643 & $(4.743)$ & 0.443 \\
\hline Intercept & 220.265 & $(2.741)$ & 0.000 & 230.934 & $(2.977)$ & 0.000 \\
\hline$R^{2}$ & & 0.202 & & & 0.223 & \\
\hline \multicolumn{7}{|l|}{ Unconditional Gap } \\
\hline Recent immigrants & -10.882 & $(3.752)$ & 0.004 & -14.952 & $(6.780)$ & 0.036 \\
\hline Not recent immigrants & -17.857 & $(3.198)$ & 0.000 & -15.544 & $(6.654)$ & 0.027 \\
\hline \multicolumn{7}{|l|}{ Recent Immigrants with } \\
\hline \multicolumn{7}{|l|}{$\overline{\text { Foreign Mother Tongue }}$} \\
\hline$\overline{\text { Literacy }}$ & 3.544 & $(0.225)$ & 0.000 & 3.629 & $(0.208)$ & 0.000 \\
\hline Literacy*Recent NESB & 1.129 & $(0.694)$ & 0.104 & $\ldots$ & $\ldots$ & $\ldots$ \\
\hline Literacy*Recent Spanish & $\ldots$ & $\ldots$ & $\ldots$ & -1.755 & $(1.760)$ & 0.319 \\
\hline Literacy*Recent Other & $\ldots$ & $\ldots$ & $\ldots$ & 2.879 & $(1.063)$ & 0.007 \\
\hline Literacy*Not Recent NESB & 1.230 & $(0.428)$ & 0.004 & $\ldots$ & $\ldots$ & $\ldots$ \\
\hline Literacy*Not Recent Spanish & $\ldots$ & $\ldots$ & $\ldots$ & -1.351 & $(1.380)$ & 0.327 \\
\hline Literacy*Not Recent Other & $\ldots$ & $\ldots$ & $\ldots$ & 0.680 & $(1.380)$ & 0.622 \\
\hline Recent NESB & -0.426 & $(3.619)$ & 0.906 & $\ldots$ & $\ldots$ & $\ldots$ \\
\hline Recent Spanish & $\ldots$ & $\ldots$ & $\ldots$ & -23.748 & $(7.821)$ & 0.002 \\
\hline Recent Other & $\ldots$ & $\ldots$ & $\ldots$ & 12.822 & $(7.171)$ & 0.074 \\
\hline Not Recent NESB & -8.352 & $(2.922)$ & 0.004 & $\ldots$ & $\cdots$ & $\ldots$ \\
\hline Not Recent Spanish & $\ldots$ & $\ldots$ & $\ldots$ & -23.605 & $(8.836)$ & 0.008 \\
\hline Not Recent Other & $\ldots$ & $\ldots$ & $\ldots$ & 21.330 & $(5.887)$ & 0.000 \\
\hline Intercept & 220.173 & $(2.687)$ & 0.000 & 231.051 & $(2.877)$ & 0.000 \\
\hline R-Squared & & 0.202 & & & 0.240 & \\
\hline \multicolumn{7}{|l|}{ Unconditional Gap } \\
\hline Recent NESB & -13.842 & $(4.228)$ & 0.001 & $\ldots$ & $\ldots$ & $\ldots$ \\
\hline Recent Spanish & $\ldots$ & $\ldots$ & $\ldots$ & -17.587 & $(6.406)$ & 0.010 \\
\hline Recent Other & $\ldots$ & $\ldots$ & $\ldots$ & 20.219 & $(6.904)$ & 0.007 \\
\hline Not Recent NESB & -23.368 & $(3.156)$ & 0.000 & $\ldots$ & $\ldots$ & $\ldots$ \\
\hline Not Recent Spanish & $\ldots$ & $\ldots$ & $\ldots$ & -21.282 & $5(.859)$ & 0.001 \\
\hline Not Recent Other & $\ldots$ & $\ldots$ & $\ldots$ & 21.816 & $5(.258)$ & 0.000 \\
\hline
\end{tabular}

Notes: Dependent variable is constructed by merging 4-digit occupation codes with 14 document literacy descriptors in the $\mathrm{O}^{*} \mathrm{NET}$ data. For more detail, see section 3.3. With the exception of the dependent variable, the estimation is identical to that reported in Tables 5 . 
Figure 1: Distribution of document literacy levels of immigrants in Australia, Canada, and the United States
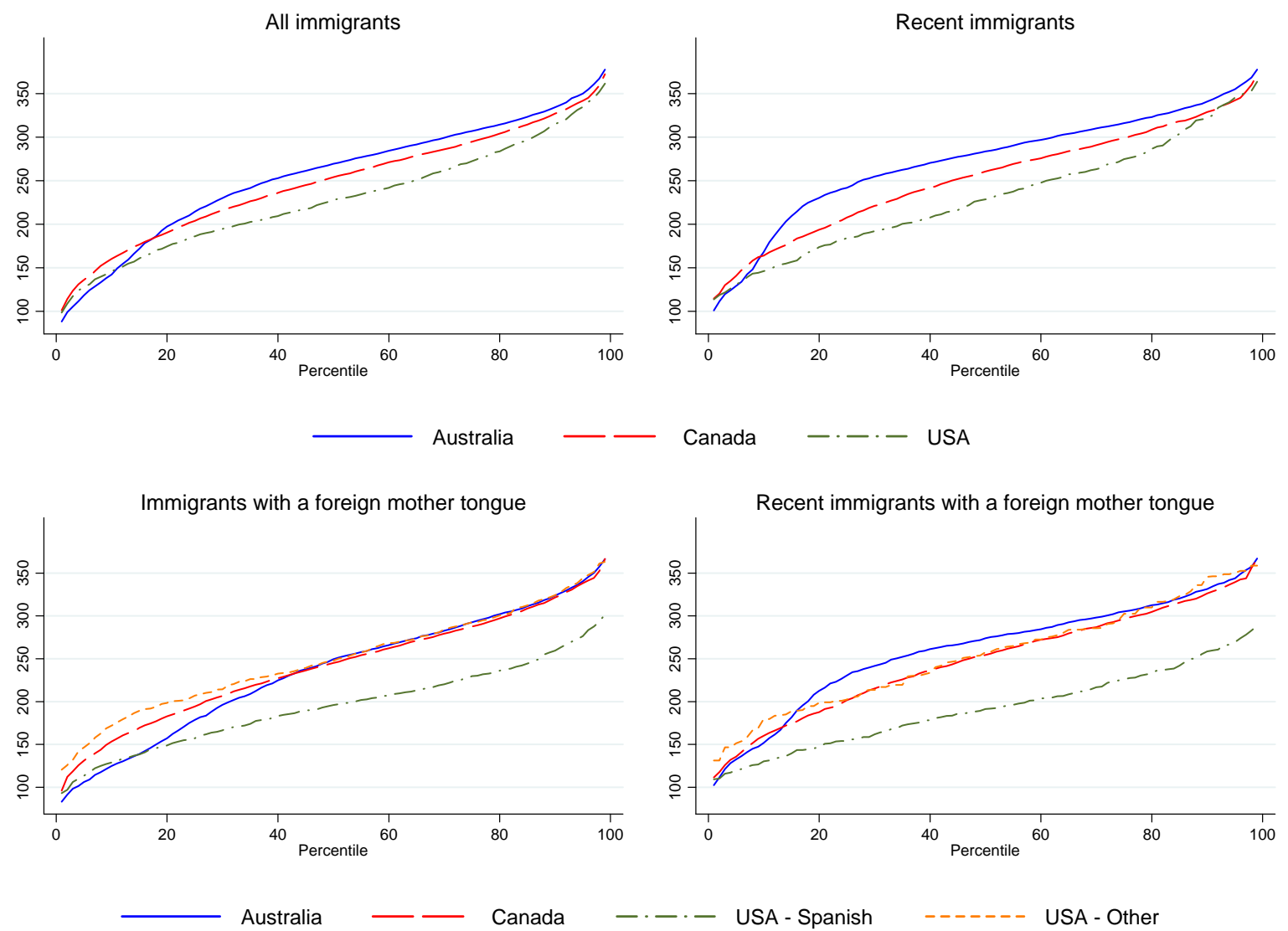

Notes: Plotted percentiles are the unweighted averages of 5 percentile estimates using each plausible value separately. Sample is restricted to individuals aged 18-64 and excludes students and the self-employed. 
Figure 2: Distribution of document literacy levels of Chinese immigrants in Australia, and the United States

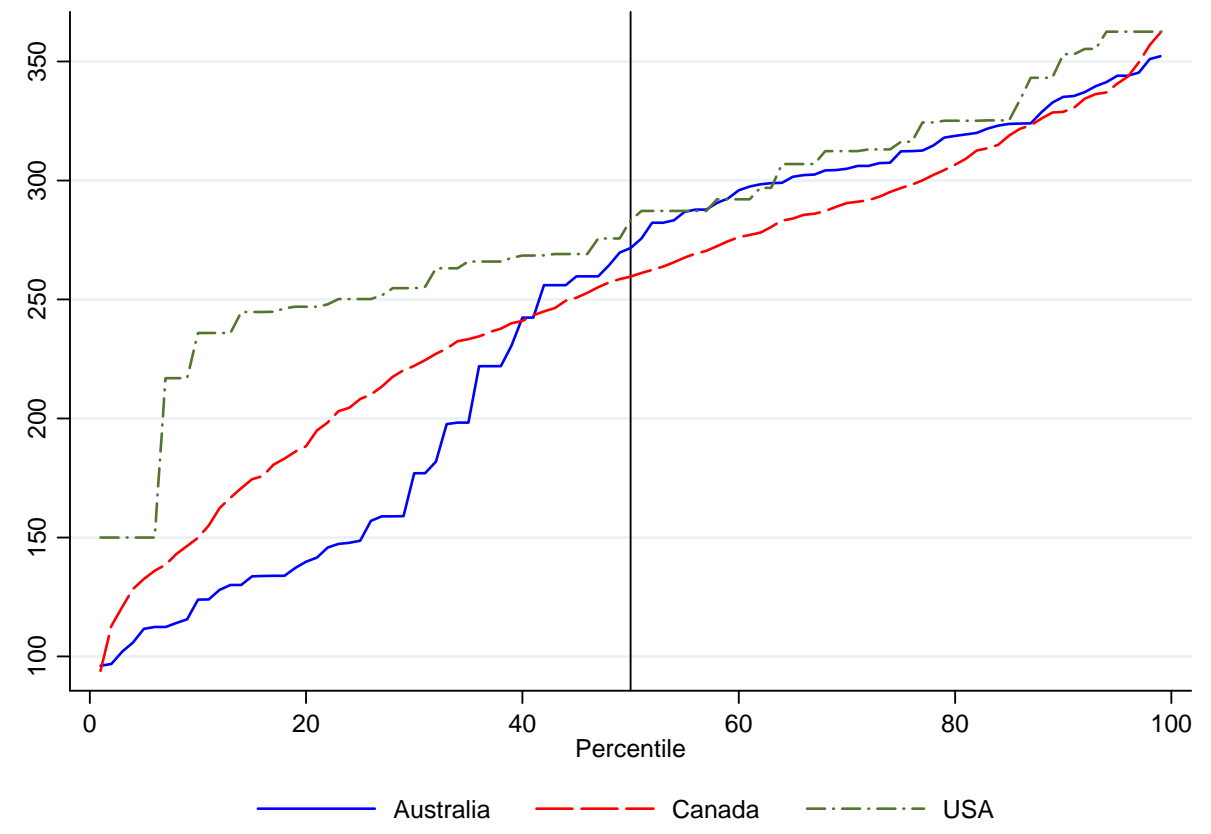

Notes: Plotted percentiles are the unweighted averages of 5 percentile estimates using each plausible value separately. Sample is restricted to individuals aged 18-64 and excludes students and the self-employed. 
Figure 3: Predicted immigrant employment rate differentials by document literacy level
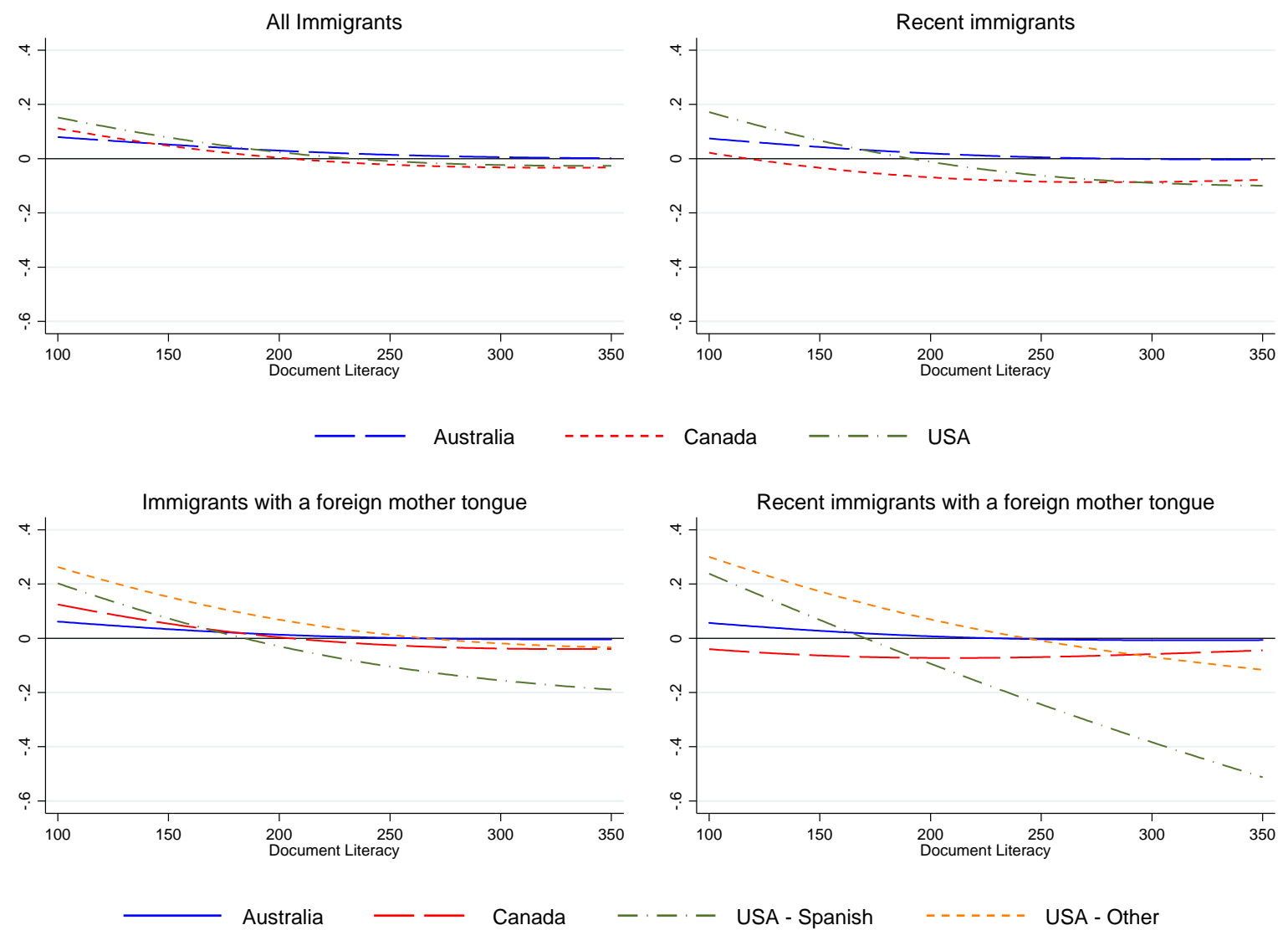

Notes: Predictions are derived from the Probit model estimates in Appendix Table 1. 
Figure 4: Predicted immigrant unemployment rates differentials by document literacy level
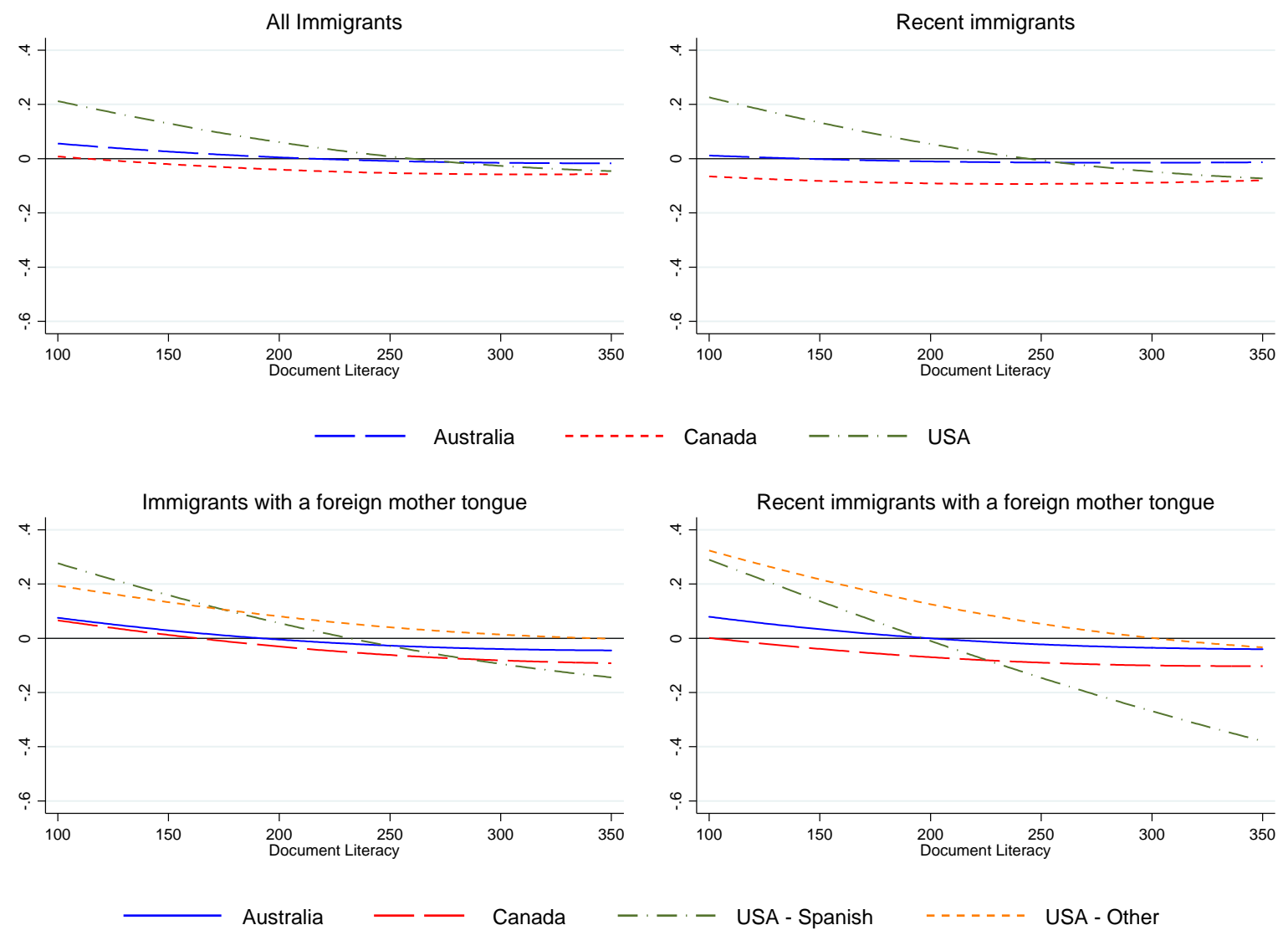

Notes: Predictions are derived from the Probit model estimates in Appendix Table 2. 
Table A.1: Probit employment regression conditional on document literacy level

\begin{tabular}{|c|c|c|c|c|c|c|c|c|c|}
\hline \multirow[b]{3}{*}{ All Immigrants } & \multicolumn{3}{|c|}{ Australia } & \multicolumn{3}{|c|}{ Canada } & \multicolumn{3}{|c|}{ United States } \\
\hline & \multirow{3}{*}{$\begin{array}{l}\text { coeff. } \\
0.069\end{array}$} & \multirow{2}{*}{\multicolumn{2}{|c|}{$\begin{array}{l}\text { Jackknife } \\
\text { Std. Err }\end{array}$}} & \multirow[t]{2}{*}{ coeff. } & \multicolumn{2}{|l|}{$\begin{array}{l}\text { Jackknife } \\
\text { Std. Err }\end{array}$} & \multirow[t]{2}{*}{ coeff. } & $\begin{array}{l}\text { Jackknife } \\
\text { Std. Err }\end{array}$ & \multirow[t]{2}{*}{$\mathrm{p}$} \\
\hline & & & & & & & & & \\
\hline$\overline{\text { Literacy }}$ & & $(0.005)$ & 0.000 & 0.065 & $(0.006)$ & 0.000 & 0.070 & $(0.008)$ & 0.000 \\
\hline Literacy*Immigrant & -0.008 & $(0.010)$ & 0.424 & -0.035 & $(0.013)$ & 0.007 & -0.035 & $(0.016)$ & 0.035 \\
\hline Immigrant & 0.140 & $(0.062)$ & 0.025 & -0.071 & $(0.059)$ & 0.231 & -0.028 & $(0.116)$ & 0.811 \\
\hline Intercept & 1.324 & $(0.091)$ & 0.000 & 1.365 & $(0.083)$ & 0.000 & 1.258 & $(0.125)$ & 0.000 \\
\hline \multicolumn{10}{|l|}{ Recent Immigrants } \\
\hline$\overline{\text { Literacy }}$ & 0.068 & $(0.005)$ & 0.000 & 0.064 & $(0.006)$ & 0.000 & 0.070 & $(0.008)$ & 0.000 \\
\hline Literacy*Recent & -0.012 & $(0.016)$ & 0.461 & -0.038 & $(0.015)$ & 0.010 & -0.060 & $(0.024)$ & 0.014 \\
\hline Literacy*Not Recent & -0.004 & $(0.013)$ & 0.750 & -0.027 & $(0.016)$ & 0.082 & -0.003 & $(0.020)$ & 0.870 \\
\hline Recent Immigrants & 0.070 & $(0.102)$ & 0.492 & -0.409 & $(0.094)$ & 0.000 & -0.203 & $(0.164)$ & 0.216 \\
\hline Not Recent Immigrants & 0.178 & $(0.073)$ & 0.015 & 0.195 & $(0.086)$ & 0.024 & 0.259 & $(0.162)$ & 0.111 \\
\hline Intercept & 1.330 & $(0.092)$ & 0.000 & 1.412 & $(0.082)$ & 0.000 & 1.281 & $(0.124)$ & 0.000 \\
\hline \multicolumn{10}{|l|}{ Recent Immigrants with } \\
\hline \multicolumn{10}{|l|}{ Foreign Mother Tongue } \\
\hline$\overline{\text { Literacy }}$ & 0.068 & $(0.005)$ & 0.000 & 0.064 & $(0.006)$ & 0.000 & 0.070 & $(0.008)$ & 0.000 \\
\hline Literacy*Recent NESB & -0.013 & $(0.019)$ & 0.492 & -0.021 & $(0.019)$ & 0.277 & $\ldots$ & $\ldots$ & $\ldots$ \\
\hline Literacy*Recent Spanish & $\ldots$ & $\ldots$ & $\ldots$ & $\ldots$ & $\ldots$ & $\ldots$ & -0.125 & $(0.051)$ & 0.015 \\
\hline Literacy*Recent Other & $\ldots$ & $\ldots$ & $\ldots$ & $\ldots$ & $\ldots$ & $\ldots$ & -0.099 & $(0.035)$ & 0.005 \\
\hline Literacy*Not Recent NESB & -0.009 & $(0.017)$ & 0.576 & -0.046 & $(0.013)$ & 0.001 & $\ldots$ & $\ldots$ & $\ldots$ \\
\hline Literacy*Not Recent Spanish & $\ldots$ & $\ldots$ & $\ldots$ & $\ldots$ & $\ldots$ & $\ldots$ & -0.040 & $(0.031)$ & 0.194 \\
\hline Literacy*Not Recent Other & $\ldots$ & $\ldots$ & $\ldots$ & $\ldots$ & $\ldots$ & $\ldots$ & -0.013 & $(0.046)$ & 0.770 \\
\hline Recent NESB & 0.006 & $(0.116)$ & 0.962 & -0.381 & $(0.101)$ & 0.000 & $\ldots$ & $\ldots$ & $\ldots$ \\
\hline Recent Spanish & $\ldots$ & $\ldots$ & $\ldots$ & $\ldots$ & $\ldots$ & $\ldots$ & -0.680 & $(0.272)$ & 0.012 \\
\hline Recent Other & $\ldots$ & $\ldots$ & $\ldots$ & $\ldots$ & $\ldots$ & $\ldots$ & 0.183 & $(0.316)$ & 0.563 \\
\hline Not Recent NESB & 0.066 & $(0.101)$ & 0.515 & 0.208 & $(0.074)$ & 0.005 & $\ldots$ & $\ldots$ & $\ldots$ \\
\hline Not Recent Spanish & $\ldots$ & $\ldots$ & $\ldots$ & $\ldots$ & $\ldots$ & $\ldots$ & 0.003 & $(0.204)$ & 0.987 \\
\hline Not Recent Other & $\ldots$ & $\ldots$ & $\ldots$ & $\ldots$ & $\ldots$ & $\ldots$ & 0.333 & $(0.185)$ & 0.072 \\
\hline Intercept & 1.350 & $(0.092)$ & 0.000 & 1.414 & $(0.084)$ & 0.000 & 1.305 & $(0.121)$ & 0.000 \\
\hline
\end{tabular}

Notes: Dependent variable is a dummy variable indicating whether an individual worked at any time in the past year. Reported coefficients $\bar{b}$ are unweighted averages of five probit estimates $\bar{b}_{j}$, each using one of the five plausible values of literacy and the population weights. Standard errors are estimated using $\operatorname{Var}(\bar{b})=J^{-1} \sum_{j} \operatorname{Var}\left(\bar{b}_{j}\right)+$ $(J+1)(J(J-1))^{-1} \sum_{j}\left(\bar{b}_{j}-\bar{b}\right)$, where $\operatorname{Var}\left(\bar{b}_{j}\right)$ is estimated using the provided jackknife replicate weights and $\mathrm{J}=5$ represents the number of plausible values. Literacy is adjusted by subtracting 225 and dividing by 10 . Regressions include a quadratic in age, controls for geographical region of residence, urban/rural area of residence, and an indicator for gender. The samples are restricted to individuals aged 18-64 who were employed in the previous 12 months. The immigrant sample is restricted to individuals who arrived in their destination country at age 14 or higher after 1955. For Australia and the United States, individuals are characterised as having a foreign mother tongue if English was not their first language learned and understood. For Canada, a foreign mother tongue is defined for first languages other than English or French. Recent immigrants refer to foreign-born individuals that have less than ten years of residence in the destination country. 
Table A.2: Probit employment regression conditional on document literacy level, labour force participants only

\begin{tabular}{|c|c|c|c|c|c|c|c|c|c|}
\hline \multirow[b]{3}{*}{ Al Jmpinconta } & \multicolumn{3}{|c|}{ Australia } & \multicolumn{3}{|c|}{ Canada } & \multicolumn{3}{|c|}{ United States } \\
\hline & coeff. & $\begin{array}{l}\text { Jackknife } \\
\text { Std. Err }\end{array}$ & $\mathrm{p}$ & coeff. & $\begin{array}{l}\text { Jackknife } \\
\text { Std. Err }\end{array}$ & $\mathrm{p}$ & coeff. & $\begin{array}{l}\text { Jackknife } \\
\text { Std. Err }\end{array}$ & $\mathrm{p}$ \\
\hline & & & & & & & & & \\
\hline Literacy & 0.049 & $(0.010)$ & 0.000 & 0.047 & $(0.009)$ & 0.000 & 0.057 & $(0.010)$ & 0.000 \\
\hline Literacy*Immigrant & -0.017 & $(0.015)$ & 0.263 & -0.017 & $(0.016)$ & 0.287 & -0.039 & $(0.023)$ & 0.083 \\
\hline Immigrant & -0.017 & $(0.110)$ & 0.878 & -0.195 & $(0.109)$ & 0.073 & 0.137 & $(0.134)$ & 0.304 \\
\hline Intercept & 1.346 & $(0.113)$ & 0.000 & 1.088 & $(0.137)$ & 0.000 & 0.962 & $(0.148)$ & 0.000 \\
\hline \multicolumn{10}{|l|}{ Recent Immigrants } \\
\hline Literacy & 0.049 & $(0.010)$ & 0.000 & 0.046 & $(0.009)$ & 0.000 & 0.057 & $(0.010)$ & 0.000 \\
\hline Literacy*Recent & -0.009 & $(0.021)$ & 0.667 & -0.014 & $(0.019)$ & 0.451 & -0.047 & $(0.034)$ & 0.165 \\
\hline Literacy*Not Recent & -0.021 & $(0.019)$ & 0.275 & -0.017 & $(0.020)$ & 0.401 & -0.029 & $(0.029)$ & 0.317 \\
\hline Recent Immigrants & -0.075 & $(0.159)$ & 0.636 & -0.359 & $(0.147)$ & 0.015 & 0.090 & $(0.199)$ & 0.650 \\
\hline Not Recent Immigrants & 0.011 & $(0.140)$ & 0.938 & -0.017 & $(0.119)$ & 0.885 & 0.188 & $(0.140)$ & 0.179 \\
\hline Intercept & 1.348 & $(0.114)$ & 0.000 & 1.107 & $(0.138)$ & 0.000 & 0.965 & $(0.147)$ & 0.000 \\
\hline \multicolumn{10}{|l|}{ Recent Immigrants with } \\
\hline \multicolumn{10}{|l|}{ Foreign Mother Tongue } \\
\hline$\overline{\text { Literacy }}$ & 0.049 & $(0.010)$ & 0.000 & 0.046 & $(0.009)$ & 0.000 & 0.058 & $(0.010)$ & 0.000 \\
\hline Literacy*Recent NESB & -0.030 & $(0.024)$ & 0.201 & -0.026 & $(0.023)$ & 0.256 & $\ldots$ & $\ldots$ & $\ldots$ \\
\hline Literacy*Recent Spanish & $\ldots$ & $\ldots$ & $\ldots$ & $\ldots$ & $\ldots$ & $\ldots$ & -0.097 & $(0.083)$ & 0.246 \\
\hline Literacy*Recent Other & $\ldots$ & $\ldots$ & $\ldots$ & $\ldots$ & $\ldots$ & $\ldots$ & -0.055 & $(0.035)$ & 0.113 \\
\hline Literacy*Not Recent NESB & -0.033 & $(0.026)$ & 0.205 & -0.033 & $(0.019)$ & 0.086 & $\ldots$ & $\ldots$ & $\ldots$ \\
\hline Literacy*Not Recent Spanish & $\ldots$ & $\ldots$ & $\ldots$ & $\ldots$ & $\ldots$ & $\ldots$ & -0.035 & $(0.036)$ & 0.332 \\
\hline Literacy*Not Recent Other & $\ldots$ & & $\ldots$ & $\ldots$ & $\ldots$ & $\ldots$ & 0.009 & $(0.060)$ & 0.876 \\
\hline Recent NESB & -0.077 & $(0.162)$ & 0.637 & -0.322 & $(0.145)$ & 0.027 & $\ldots$ & $\ldots$ & $\ldots$ \\
\hline Recent Spanish & $\ldots$ & $\ldots$ & $\ldots$ & $\ldots$ & $\ldots$ & $\ldots$ & -0.275 & $(0.414)$ & 0.507 \\
\hline Recent Not Spanish & $\ldots$ & $\ldots$ & $\ldots$ & $\ldots$ & $\ldots$ & $\ldots$ & 0.423 & $(0.203)$ & 0.037 \\
\hline Not Recent NESB & -0.124 & $(0.166)$ & 0.453 & -0.053 & $(0.132)$ & 0.688 & $\ldots$ & $\ldots$ & $\ldots$ \\
\hline Not Recent Spanish & $\ldots$ & $\ldots$ & $\ldots$ & $\ldots$ & $\ldots$ & $\ldots$ & 0.498 & $(0.283)$ & 0.079 \\
\hline Not Recent Other & $\ldots$ & $\ldots$ & $\ldots$ & $\ldots$ & $\ldots$ & $\ldots$ & 0.218 & $(0.306)$ & 0.476 \\
\hline Intercept & 1.365 & $(0.115)$ & 0.000 & 1.121 & $(0.141)$ & 0.000 & 0.942 & $(0.149)$ & 0.000 \\
\hline
\end{tabular}

Notes: Dependent variable is a dummy variable indicating whether an individual's current work status is employed. Reported coefficients $\bar{b}$ are unweighted averages of five probit estimates $\bar{b}_{j}$, each using one of the five plausible values of literacy and the population weights. Standard errors are estimated using $\operatorname{Var}(\bar{b})=J^{-1} \sum_{j} \operatorname{Var}\left(\bar{b}_{j}\right)+(J+1)(J(J-$ $1))^{-1} \sum_{j}\left(\bar{b}_{j}-\bar{b}\right)$, where $\operatorname{Var}\left(\bar{b}_{j}\right)$ is estimated using the provided jackknife replicate weights and $\mathrm{J}=5$ represents the number of plausible values. Literacy is adjusted by subtracting 225 and dividing by 10 . Regressions include a quadratic in age, controls for geographical region of residence, urban/rural area of residence, and an indicator for gender. The samples are restricted to individuals aged 18-64 who were employed in the previous 12 months. The immigrant sample is restricted to individuals who arrived in their destination country at age 14 or higher after 1955. For Australia and the United States, individuals are characterised as having a foreign mother tongue if English was not their first language learned and understood. For Canada, a foreign mother tongue is defined for first languages other than English or French. Recent immigrants refer to foreign-born individuals that have less than ten years of residence in the destination country. 


\section{University Library}

\section{- M M N E R VA A gateway to Melbourne's research publications}

Minerva Access is the Institutional Repository of The University of Melbourne

Author/s:

Clarke, A;Skuterud, M

Title:

A comparative analysis of immigrant skills and their utilization in Australia, Canada, and the USA

Date:

2016-07-01

Citation:

Clarke, A. \& Skuterud, M. (2016). A comparative analysis of immigrant skills and their utilization in Australia, Canada, and the USA. JOURNAL OF POPULATION ECONOMICS, 29 (3), pp.849-882. https://doi.org/10.1007/s00148-016-0591-2.

Persistent Link:

http://hdl.handle.net/11343/283323 